\title{
UMA ANÁLISE DO PAPEL DAS ESCOLAS E DAS REDES DE ENSINO SOBRE AS DESIGUALDADES DE OPORTUNIDADES EDUCACIONAIS
}

\author{
Priscilla Albuquerque Tavares * \\ Rafael Camelo $^{\dagger}$ \\ Luan Pires Paciência $\ddagger$
}

\begin{abstract}
Resumo
Este artigo contribui para a literatura de desigualdades de oportunidades educacionais ao separar os determinantes do aprendizado entre circunstâncias e esforços, com foco na capacidade de atuação dos gestores das redes e das escolas. Os resultados mostram que entre $10 \%$ e $15 \%$ da desigualdade de notas estão sob controle dos órgãos centrais, mas fogem ao controle dos diretores escolares. A metodologia também permite estimar em que medida as circunstâncias afetam a desigualdade de notas via interação com os esforços dos gestores. Os resultados mostram que entre $10 \%$ e $23 \%$ da desigualdade atribuída ao perfil dos alunos pode ser influenciada por políticas educacionais. Esses resultados sugerem que os esforços dos gestores podem amenizar os efeitos das circunstâncias sobre a desigualdade.
\end{abstract}

Palavras-chave: Desigualdade educacional; Igualdade de oportunidades; Efeito-escola.

\begin{abstract}
This article contributes to the literature on inequalities of educational opportunities by separating the determinants in circumstances and efforts, focusing on the ability of managers and schools to act. The results show that between $10 \%$ and $15 \%$ of grade inequality can be influenced by educational central administration, but not by school principals. The methodology also allows us to estimate to what extent circumstances affect inequality through its interaction with managers' efforts. The results show that between $10 \%$ and $23 \%$ of inequality can be influenced by educational policies. These results suggest that managers may attenuate the effects of circumstances on an inequality.
\end{abstract}

Keywords: Educational inequality; Equality of opportunity; School effect. JEL classification: I21, I28

DOI: http://dx.doi .org/10.11606/1980-5330/ea154846

\footnotetext{
* Escola de Economia de São Paulo (FGV). E-mail: priscilla.tavares@fgv.br.

† Plano CDE. E-mail: rafael.camelo@gmail.com.

‡ Fundação Itaú Social. E-mail: luan.paciencia@gmail.com.
} 


\section{Introdução}

A pesquisa sobre a qualidade da educação em países desenvolvidos e em desenvolvimento tem há muito tempo se debruçado sobre os fatores que influenciam o desempenho cognitivo dos estudantes, medido por testes de proficiência padronizados. A maioria dos estudos considera a abordagem da função de produção educacional, segundo a qual o desempenho escolar está relacionado a características dos alunos e de sua família, aos insumos escolares e aos fatores que envolvem o entorno e a comunidade escolar. Há consenso na literatura sobre a importância que o background familiar dos estudantes exerce sobre o aprendizado. Já em relação aos fatores ligados às escolas, os resultados não são inequívocos.

O impacto do aumento dos gastos em educação sobre resultados escolares de curto (frequência e desempenho) ou longo prazo (anos de estudos, ingresso no ensino superior, empregabilidade e salários) é vastamente investigado na literatura empírica e os resultados são bastante variados. Por um lado, não há muitas evidências de efeitos significativos dos insumos físicos, da infraestrutura e dos recursos pedagógicos sobre resultados escolares. O resultado desses trabalhos reduziu a importância relativa dos insumos escolares, em comparação ao papel que o perfil da família exerce sobre o aprendizado, colocando um olhar pessimista para a definição das políticas públicas em educação (Hanushek 1986, Betts 1996, Heckman et al. 1996, Barros et al. 2001, Albernaz et al. 2002, Hanushek \& Luque 2003, Brooke \& Soares 2011)

Parte dessas conclusões advém da dificuldade que a literatura tem em medir adequadamente certos construtos. O maior exemplo refere-se à qualidade do professor. Medidas tradicionais, como a qualificação acadêmica, apresentam pouca associação com o aprendizado dos estudantes, tornando difícil a identificação de quais características definem um bom professor. As medidas provavelmente mais importantes (como dedicação, esforço, paciência, didática) são, em geral, não observáveis. Estratégias empíricas dedicadas a identificar o impacto dessas características sobre o aprendizado levam à conclusão de que o insumo escolar mais importante é o professor (Aaronson et al. 2007, Rivkin et al. 2005, Rockoff 2004, Buddin \& Zamarro 2009). Da mesma maneira, outro conjunto de estudos encontra efeitos significantes e positivos, embora de magnitude reduzida em alguns casos, do aumento geral dos gastos por aluno ou da introdução de políticas específicas, como a redução do tamanho das turmas, a mudança da jornada escolar e políticas de melhoria na qualificação dos professores (Glewee et al. 2011, Gibbons \& McNally 2013). Esses resultados, que são mais frequentemente verificados nos estudos para países em desenvolvimento e cujos efeitos tendem a ser maiores sobre os estudantes em desvantagens socioeconômicas e educacionais, devolvem a relevância do papel da escola sobre a melhoria da qualidade da educação.

Há outra linha de investigação que se debruça sobre a estimação do chamado efeito-escola. Nesse caso, os resultados também concluem pela influência positiva do conjunto de atributos escolares sobre o aprendizado dos estudantes. Isso porque se encontram resultados positivos sobre a redução da desigualdade educacional diante de um aumento geral da qualidade das escolas para um patamar de excelência (Felício \& Fernandes 2005). Além disso, também é possível identificar grupos de escolas que conseguem elevar o desempenho dos alunos para além do esperado para suas condições socioeconômicas (Lee 2010, Alves 2008, Andrade \& Soares 2008). 
Do ponto de vista conceitual, a maioria dos estudos separa os fatores que impactam a proficiência entre atributos extra e intraescolares. Dentre os, fatores extraescolares, estão o perfil dos alunos e seu background familiar, bem como o contexto social no qual a escola está inserida, caracterizado por sua localização, condições socioeconômicas do bairro, indicadores de violência do entorno etc. Já os fatores intraescolares referem-se a todos os seus recursos financeiros, físicos e pedagógicos, infraestrutura, perfil do corpo docente e dos gestores, além de processos administrativos e pedagógicos que determinam seu funcionamento. Em geral, considera-se que os fatores extraescolares são dados para as escolas, enquanto que os fatores intraescolares "podem ser mudados por sua ação interna" (Soares 2007).

Essa separação entre fatores extra e intraescolares coloca um olhar estanque sobre as possibilidades de atuação dos gestores, que pode não refletir completamente a realidade das escolas públicas. Por um lado, há alguns fatores intraescolares que os gestores não conseguem influenciar. O exemplo mais emblemático para escolas públicas é que, em geral, os diretores não possuem autonomia para a contratação e demissão de professores e não decidem sobre políticas de avaliação e remuneração dos docentes. Assim, se esses fatores intraescolares não são passíveis de mudanças, o potencial de atuação das escolas seria ainda menor.

Por outro lado, o perfil determinista dos fatores extraescolares pode ser minorado, se parte dos seus efeitos sobre o aprendizado ocorrer de forma indireta, por meio de sua interação com os fatores intraescolares. Por exemplo, um canal indireto de atuação da escolaridade dos pais sobre o desempenho pode se dar via sua participação na vida escolar dos filhos e da formação de atitudes favoráveis ao trabalho da escola. As escolas podem 'se esforçar' para desenvolver um bom relacionamento com os pais, incentivando sua inserção nas atividades escolares e fornecendo-lhes informações sobre o desempenho dos filhos.

Em resumo, nem todos os fatores intraescolares estão ao alcance da atuação direta dos gestores que atuam diretamente nas escolas. Além disso, embora os fatores extraescolares não possam ser diretamente alterados pelos diretores, é possível identificar intervenções que atuem sobre as interações existentes entre os fatores extra e intraescolares e que possam potencializar (ou reduzir) os efeitos benéficos (deletérios) que os primeiros exercem sobre o aprendizado.

Há outro aspecto importante a ser considerado. A tomada de decisões sobre a alocação de recursos e a implantação de políticas educacionais que afetam as escolas públicas ocorre em, pelo menos, dois níveis: a escola e a rede de ensino à qual ela pertence. Assim, embora muitas decisões escapem do controle dos diretores das escolas, devido à baixa autonomia que possuem, parte delas está ao alcance da atuação dos gestores de níveis hierárquicos mais elevados (p.e., o secretário da educação). Apesar disso, a literatura não faz distinção entre o impacto potencial das redes de ensino e das próprias escolas sobre a redução das desigualdades educacionais.

Diante desses argumentos, nós optamos por adotar a abordagem da desigualdade de oportunidades de Roemer (1998), como forma alternativa para o estudo dos fatores que impactam as diferenças de desempenho entre as escolas e que vai além da separação dos determinantes do aprendizado em fatores extra e intraescolares.

O conceito de desigualdade de oportunidades sugere que os determinantes 
de um resultado individual (como a renda, por exemplo) podem ser separados em circunstâncias e esforços. As circunstâncias são os fatores exógenos que influenciam o resultado, mas não podem ser alterados pelo indivíduo. Os esforços, por sua vez, são os determinantes do resultado que podem ser afetados pela escolha individual ${ }^{1}$.

Nós aplicamos essa abordagem para estudar os fatores associados à desigualdade de notas do ensino fundamental $\left(5^{\circ}\right.$ e $9^{\circ}$ ano) nas escolas públicas brasileiras. A partir de um modelo conceitual e dos dados da Prova Brasil e do Censo Escolar 2011, construímos medidas dos esforços e das circunstâncias que se associam ao desempenho escolar. Ou seja, observamos fatores associados ao aprendizado sobre os quais as redes de ensino e/ou as escolas podem exercer influência, bem como aqueles que estão fora de seu controle.

A estratégia empírica adotada nos permite quantificar o grau da desigualdade de oportunidades associada às notas no ensino fundamental ${ }^{2}$. Esta é calculada a partir da diferença entre medidas de desigualdades de notas das distribuições observada e contrafactual (caso as circunstâncias fossem equalizadas). Ela ainda considera que parte dos determinantes do desempenho (os esforços) são endógenos, no sentido de também serem influenciados pelas circunstâncias.

Dessa forma, nossa estratégia apresenta duas vantagens em relação às demais abordagens de mensuração do efeito-escola. A primeira diz respeito à própria interpretação desse efeito. O efeito-escola tradicional corresponde ao efeito total dos atributos escolares sobre o aprendizado, sem distinção entre circunstâncias e esforços, enquanto nós fazemos essa separação. Também apresentamos estimativas para a diferença entre o efeito-escola e o efeito-rede. Isso permite distinguir entre o impacto potencial que cada gestor dos sistemas de ensino exerce.

Além disso, obtemos os efeitos direto e indireto das circunstâncias sobre o desempenho escolar. Os efeitos indiretos dizem respeito à influência que as circunstâncias exercem sobre a desigualdade de notas por meio da sua interação com as decisões tomadas pelas redes de ensino e pelas escolas. Assim, identificamos em que medida as políticas disponíveis aos gestores educacionais podem potencializar ou amenizar os impactos das circunstâncias sobre o aprendizado.

Utilizamos essa abordagem para estudar a desigualdade de notas no ensino fundamental entre as escolas públicas urbanas brasileiras. Os resultados sugerem que o efeito-escola é de cerca de $40 \%-45 \%$ e o efeito-rede é da ordem de $50 \%-60 \%$. Com isso, mostramos que entre $10 \%$ e $15 \%$ da desigualdade de notas está sob controle de políticas educacionais estabelecidas pelos órgãos centrais, mas fogem ao controle direto dos diretores das escolas.

A estratégia empírica também permite distinguir entre os efeitos direto e indireto da desigualdade de oportunidades. Os esforços são considerados endógenos e, portanto, são afetados pelas circunstâncias. Os resultados mostram que entre $10 \%$ e $23 \%$ das desigualdades de notas devidas ao perfil dos alunos podem ser influenciados por políticas educacionais. Além disso, as estima-

\footnotetext{
${ }^{1}$ Se considerarmos o salário como o resultado individual de interesse, o gênero, a cor/raça e o background familiar poderiam ser considerados circunstâncias. As decisões do indivíduo quanto ao seu próprio nível de escolaridade, posição no mercado de trabalho, migração etc. seriam medidas de esforço.

${ }^{2} \mathrm{O}$ modelo conceitual adotado é o do Soares (2007) e a estratégia empírica é semelhante à proposta por Bourguignon et al. (2007). Ambos serão detalhados nas próximas seções.
} 
tivas dos efeitos indiretos mostram que a redução da desigualdade de notas por meio da equalização dos recursos físicos ou da qualidade dos professores exige a implantação de políticas educacionais complementares.

Este artigo está dividido em mais quatro seções, além desta introdução. A Seção 2 apresenta o modelo educacional conceitual no qual nos baseamos para distinguir entre circunstâncias e esforços, além da metodologia de decomposição dos índices de desigualdade e da estratégia empírica. A Seção 3 descreve os dados utilizados e as estatísticas descritivas. A Seção 4 discute os resultados encontrados e, finalmente, a Seção 5 conclui.

\section{Modelo Conceitual, Decomposição e Estratégia Empírica}

Neste artigo, estamos interessados em medir a parcela das desigualdades de notas devida às desigualdades de oportunidades. Roemer (1998) associa oportunidades ao impacto dos fatores sobre os quais os indivíduos não têm controle - as circunstâncias. Nesta seção, apresentamos o modelo conceitual usado para identificar as variáveis de circunstância e de esforço, bem como a abordagem adotada na estimação e na decomposição dos índices de desigualdade de notas.

A adoção de um modelo conceitual que sintetiza os diferentes fatores que impactam o aprendizado torna menos arbitrária a definição de quais desses atributos são circunstâncias e quais deles podem ser influenciados por ações dos gestores escolares ou das redes de ensino e, portanto, se caracterizam como esforços. Nós nos baseamos no modelo proposto por Soares $(2007)^{3}$. $\mathrm{O}$ autor inicialmente distingue entre as influências externas, que "fogem completamente ao controle interno da escola", e suas características estruturais ou fatores passíveis de mudança pela atuação dos gestores. A descrição do autor para os constructos de cada grupo é feita a seguir. Consideraremos o primeiro grupo de fatores como as circunstâncias e o segundo grupo como os esforços que as escolas ou redes de ensino podem realizar.

Dentre as circunstâncias, a primeira refere-se ao conjunto de leis e normas às quais a escola está submetida. Em geral, essas normas são específicas à rede de ensino à qual a escola pertence. O mesmo acontece com montante de recursos financeiros, que também se coloca como uma limitação para as escolas públicas. Dentro de uma rede de ensino, em geral há regras rígidas que determinam o volume de recursos que será alocado a cada escola.

O tamanho da escola, expresso pelo número de alunos atendidos, está diretamente relacionado à complexidade da gestão escolar, assim como a diversidade de etapas de ensino oferecidas: é razoável supor que é mais fácil administrar uma escola pequena que oferece apenas o ensino fundamental, por exemplo.

A localização da escola, por sua vez, determina o grau de relacionamento da escola com instâncias administrativas superiores (Secretaria da Educação). Além disso, a localidade também se relaciona com o entorno escolar e, portanto, com as condições de segurança física e patrimonial das pessoas que frequentam a escola e com as influências externas que recaem sobre os alu-

\footnotetext{
${ }^{3} \mathrm{O}$ modelo desenvolvido por Soares (2007) é baseado em outros modelos similares (Coleman 1966, Lee et al. 1993, Scheerens \& Bosker 1997, Cohen et al. 2002) e apresenta uma discussão dos efeitos de cada constructo teórico com ênfase ao caso de escolas públicas, baseada em extensa revisão da literatura nas áreas de Educação, Pedagogia e Economia.
} 
nos (disponibilidade e consumo de drogas lícitas ou ilícitas). O entorno também afeta as condições materiais às quais a escola está submetida (depredação, furto, roubo).

Os perfis dos gestores, do corpo docente e dos alunos atendidos também se colocam como circunstâncias. Nas escolas públicas, raramente os diretores são escolhidos em processos que envolvam professores e pais e sim por indicação de instâncias superiores ou por concursos. Além disso, os gestores selecionados não possuem autonomia para definir regras de contratação, demissão, avaliação e remuneração dos professores. Estas são dadas pelas redes de ensino.

Entretanto, a formação acadêmica e a experiência dos diretores dizem respeito à sua competência administrativa e ao seu conhecimento das estratégias pedagógicas, características importantes para legitimar seu papel de liderança. Do mesmo modo, formação acadêmica e a experiência dos docentes impactam seu conhecimento específico nas suas áreas de atuação (disciplinas lecionadas) e sobre as tecnologias de ensino mais efetivas. Os gestores também têm dificuldades em elevar o tempo de dedicação do professor na escola, já que muitas vezes a composição da jornada de trabalho do professor exige que este lecione em várias escolas e as regras de alocação dos docentes favorecem a elevada rotatividade.

Por fim, e talvez mais importante, está o nível socioeconômico dos estudantes. As condições materiais das famílias e o nível educacional dos pais afetam o consumo de bens culturais, a valorização e o incentivo que os pais dão aos estudos, bem como o tempo que dedicam a acompanhar a vida escolar dos filhos e a qualidade dessa interação. A composição do corpo discente (quanto à idade, gênero, cor/raça), por sua vez, afeta as inter-relações entre os estudantes e, portanto, seu comportamento disciplinar e atitudes frente aos estudos criando ambientes mais ou menos propícios ao aprendizado (efeito dos pares).

Muitos outros fatores colocam-se como esforços dos gestores das escolas ou das redes de ensino. Podemos separá-los em duas grandes dimensões que se relacionam. A primeira delas refere-se aos recursos utilizados na escola. A disponibilidade e condições de uso dos equipamentos para uso administrativo e dos espaços e recursos didático-pedagógicos (biblioteca, computadores e internet para uso dos alunos, laboratórios, livros, materiais paradidáticos etc.) é de responsabilidade da escola. Em relação aos recursos didático-pedagógicos, as práticas da escola quanto ao acesso dos alunos a esses recursos e à sua utilização por parte dos professores são ainda mais importantes do que apenas sua existência. Dentre esses recursos, destaca-se o livro didático. A manutenção, conservação e limpeza das dependências do prédio escolar e o ambiente físico das salas de aula também fazem parte dessa dimensão.

A segunda dimensão do esforço refere-se à gestão escolar. A boa administração de uma escola exige, em primeiro lugar, que o planejamento escolar esteja centrado no processo de ensino-aprendizagem e que se estabeleçam objetivos bem definidos, conhecido por todos. Para isso, é importante que a liderança do diretor atue no sentido de valorizar a opinião dos professores na tomada de decisões e de facilitar a coesão do corpo docente de forma a favorecer a troca de experiências e ajuda mútua entre eles. Também é fundamental monitorar os resultados educacionais, compartilhá-los com o corpo docente e estabelecer ações com base nas expectativas de sucesso escolar dos estudantes. Nesse sentido, a participação dos pais nas atividades escolares ou 
até nas decisões tomadas pela escola pode criar atitudes das famílias frente à escola que sejam favoráveis ao aprendizado.

A gestão pedagógica define as diretrizes a serem adotadas na escola, que passa pelo conhecimento comum e garantia do cumprimento do currículo e pela corrente pedagógica adotada (baseada, por exemplo, em métodos tradicionais ou estratégias alternativas de ensino-aprendizagem). Outras escolhas da gestão pedagógica referem-se ao tamanho das classes e à alocação dos alunos nas turmas. Sabe-se que as classes maiores e a formação de turmas homogêneas (quanto aos resultados acadêmicos) exercem efeitos deletérios sobre o aprendizado, principalmente entre alunos com menor nível socioeconômico.

Por fim, é fundamental gerenciar o uso do tempo escolar, de forma a garantir o maior tempo de exposição dos alunos ao conteúdo. Para isso, é preciso administrar a falta dos professores e dos alunos e minimizar os problemas disciplinares que consomem o tempo das aulas.

Além disso, a gestão escolar influencia o chamado clima escolar, que se expressa pelas relações interpessoais entre alunos, professores e funcionários. A qualidade da interação aluno-professor é especialmente importante, uma vez que as atitudes de acolhimento e incentivo dos professores e o respeito mútuo entre professores e alunos afetam a capacidade dos docentes em gerir a sala de aula e, portanto, de produzir um ambiente adequado ao aprendizado.

Esse modelo conceitual revisa os diversos fatores que exercem influência sobre o aprendizado, com foco na realidade das escolas públicas. Embora os constructos possuam relações entre si, essa forma de apresentação dos determinantes do desempenho escolar traz objetividade na separação entre esforços e circunstâncias, ao pontuar o que está e o que não está ao alcance da atuação ou influência dos gestores que administram diretamente as escolas.

Entretanto, é importante ressaltar que muitas das circunstâncias postas para as escolas podem ser dimensões de atuação dos gestores das redes de ensino. Por exemplo, embora os diretores não tenham autonomia para escolher os professores, o perfil dos docentes e sua dedicação na escola são influenciados pelas exigências para a admissão nos concursos, nas práticas de formação continuada oferecidas e pelas regras de alocação dos professores entre as diferentes escolas, todos fatores sob controle das secretarias de educação. A definição das dimensões que se colocam como circunstâncias para as escolas e, ao mesmo tempo, esforços para as redes de ensino é importante para distinguirmos entre o impacto potencial de cada agente que gerencia os sistemas educacionais.

Em resumo, as circunstâncias podem ser definidas como variáveis exóge$n a s^{4}$. Já fatores que denotam esforço são considerados endógenos, uma vez que também podem ser afetados pelas circunstâncias. Seguindo Bourguignon et al. $(2007)^{5}$, de maneira mais formal, se a nota média da escola $i$ for denotada por $g_{i}$ e se os vetores $C_{i}$ e $E_{i}$ denotarem, respectivamente, o conjunto de variáveis de circunstância e esforço, pode-se escrever a seguinte função que descreve as notas dos estudantes:

$$
g_{i}=f\left(C_{i}, E\left(C_{i}, v_{i}\right), \varepsilon_{i}\right)
$$

\footnotetext{
${ }^{4}$ Isso não implica exogeneidade econométrica.

${ }^{5}$ Esses autores desenvolvem uma estratégia empírica para estudar a desigualdade de oportunidades associada à distribuição de salários no Brasil. Adaptamos sua abordagem de estimação e de decomposição para o estudo da desigualdade de oportunidades associada às notas dos estudantes.
} 
em que $\varepsilon$ e $v$ incluem os determinantes das notas não observados.

Se as notas forem distribuídas segundo $\Psi(g)$, a medida de desigualdade de oportunidades será dada por:

$$
\Theta_{I}=\frac{I(\Psi)-I(\widetilde{\Psi})}{I(\Psi)}
$$

em que $I($.$) é a medida de desigualdade e \Theta_{I}$ mede o efeito total que as circunstâncias exercem sobre o desempenho dos estudantes (contingente ao índice $I$ escolhido). $\widetilde{\Psi}$ representa a função distribuição de notas médias das escolas sob o contrafactual que define a igualdade de oportunidades, ou seja, no caso em que todas as escolas apresentam as mesmas circunstâncias $\left(C_{i}=\bar{C}\right)$ e, portanto, $\widetilde{g_{i}}=f\left(\bar{C}, E\left(\bar{C}, v_{i}\right), \varepsilon_{i}\right)$.

É importante ressaltar como essa medida de desigualdade de oportunidades deve ser interpretada. A igualdade de oportunidades seria observada caso a distribuição de notas entre as escolas fosse independente das circunstâncias. Isso implicaria que: a) controlando pelos esforços, as circunstâncias não exerceriam impacto direto sobre as notas e b) as circunstâncias não teriam efeito sobre os esforços e, portanto, também não exerceriam impacto indireto sobre as notas. Dessa forma, $\Theta_{I}$ mede o impacto total das circunstâncias sobre a desigualdade de notas ${ }^{6}$.

É interessante, no entanto, separar esse efeito total em dois. O efeito direto das circunstâncias sobre a desigualdade de notas é obtido por $\Theta_{I}^{d}=\frac{I(\Psi)-I\left(\widetilde{\Psi}^{d}\right)}{I(\Psi)}$, em que o contrafactual $\left(\widetilde{\Psi}^{d}\right)$ representa a distribuição de notas médias das escolas que seria observada caso as circunstâncias só afetassem o desempenho dos estudantes por meio de sua interação com as medidas de esforço das escolas e redes de ensino, ou seja, $\widetilde{g_{i}^{d}}=f\left(\bar{C}, E\left(C_{i}, v_{i}\right), \varepsilon_{i}\right)$. Já o efeito indireto é calculado pela seguinte diferença $\Theta_{I}^{i}=\Theta_{I}-\Theta_{I}^{d}$.

A estimação desse último efeito pode ajudar a conduzir especulações sobre políticas ou ações disponíveis para os gestores que potencializem ou amenizem os efeitos das circunstâncias sobre o desempenho escolar. Entretanto, é preciso ressaltar que, uma vez que não somos capazes de estimar o impacto das circunstâncias sobre os esforços, não podemos identificar diretamente esses canais de atuação.

A implementação dessas decomposições segue a seguinte estratégia empírica. Partimos do seguinte sistema de equações que relacionam o desempenho educacional com circunstâncias e esforços:

$$
\begin{gathered}
g_{i}=\alpha C_{i}+\beta E_{i}+u_{i} \\
E_{i}=\gamma C_{i}+v_{i}
\end{gathered}
$$

em que $g_{i}$ agora é o desempenho médio da $i$-ésima escola e $u_{i}$ e $v_{i}$ são termos aleatórios. Esse sistema nos permite identificar os dois indicadores de desigualdade de oportunidade de interesse.

\footnotetext{
${ }^{6}$ Bourguignon et al. (2007) argumentam que a igualdade de circunstâncias é suficiente (embora não necessária) para a igualdade de oportunidades. A igualdade de oportunidades seria atendida se $F(g \mid C)=F(g)$. Essa independência requer que a) $\frac{\partial f(C, E, \varepsilon)}{\partial C}=0$ (circunstâncias não têm impacto direto sobre as notas) e b) $G(E \mid C)=G(E)$ (circunstâncias não têm impacto indireto sobre as notas).
} 
A desigualdade de oportunidades total será calculada usando uma forma reduzida da primeira equação:

$$
g_{i}=\alpha C_{i}+\beta\left(\gamma C_{i}+v_{i}\right)+u_{i}=\delta C_{i}+\epsilon_{i}
$$

em que $\delta=\alpha+\beta \gamma$ e $\epsilon_{i}=\beta v_{i}+u_{i}$. A partir da estimativa do parâmetro $\delta$ calculamos o desempenho escolar contrafactual equalizando as medidas de circunstâncias: $\widetilde{g_{i}}=\bar{\delta} \bar{C}+\widehat{\epsilon_{i}}$.

Já para calcular o efeito direto das desigualdades de oportunidades, estimaremos os parâmetros da primeira equação do sistema, controlando diretamente pelas medidas de esforço. O desempenho contrafactual agora será calculado equalizando apenas as medidas de circunstância, mas permitindo que o esforço continue variando entre as escolas: $\widetilde{g}_{i}^{d}=\widehat{\alpha} \bar{C}_{i}+\widehat{\beta} E_{i}+\widehat{u_{i}}$.

A partir desses contrafactuais podemos calcular os índices de desigualdade. Para tanto, adotamos o índice $L$ de Theil. É importante ressaltar que a escolha desses índices específicos tem a ver com características dos dados.

Como veremos mais à frente, usaremos como medida de desempenho escolar as notas na Prova Brasil, que são calculadas usando a Teoria da Resposta ao Item (TRI). Essa técnica, usada para gerar um indicador padronizado da proficiência latente dos estudantes, requer que a média e a variância das notas sejam ajustadas a partir de uma escala arbitrária.

Com isso, conforme argumentam Ferreira \& Gignoux (2008), a aplicação de medidas de desigualdade sobre notas padronizadas não refletirá a desigualdade "original" do fenômeno, isto é, a desigualdade sem a padronização. Porém, os mesmos autores demonstram que o $L$ de Theil (entre outros índices) ainda podem ser aplicados caso o interesse não recaia sobre os valores absolutos da desigualdade, mas sobre valores relativos (que é o caso das medidas relativas de desigualdade de oportunidade).

Além do exercício básico de calcular o share da desigualdade de oportunidades, faremos um exercício adicional de estimar o peso de cada indicador de circunstância sobre a desigualdade de notas. A ideia do exercício é a mesma, de modo que equalizaremos cada indicador individualmente para medir seu peso sobre a desigualdade de notas. Os erros-padrão são gerados via bootstrap.

\section{Dados e Estatísticas Descritivas}

Nas estimações descritas na seção anterior, usamos os microdados do Censo Escolar 2011 e da Prova Brasil 2011, conduzidos pelo INEP/MEC. O Censo Escolar é coletado anualmente e abrange o universo das escolas públicas e privadas do país. Ele contém informações detalhadas no nível da escola sobre a localização, infraestrutura e recursos pedagógicos e número de matrículas por etapa de ensino.

Já a Prova Brasil é um exame de proficiência de Língua Portuguesa e Matemática, aplicado a cada dois anos a todos os alunos matriculados no $5^{\circ}$ e no $9^{\circ}$ ano do ensino fundamental. A prova abrange todas as escolas públicas brasileiras das redes municipal, estadual e federal que possuam ao menos 20 alunos matriculados em cada série avaliada. Em todas as edições, são aplicados questionários socioeconômicos e de contexto escolar aos alunos, professores, diretores e escolas. O referencial teórico que orienta a construção desses instrumentos apresenta forte aderência com o modelo conceitual apresentado na 
seção anterior, de forma que é possível extrair dos questionários proxies para todas as dimensões mencionadas.

As medidas de circunstâncias e esforços utilizadas nas estimações são construídas a partir da agregação simples de diferentes itens dos questionários. A seguir, apresentamos os indicadores incluídos nos modelos e as variáveis que os compõem ${ }^{7}$.

As dimensões de circunstâncias são as seguintes:

- Leis e normas: dummy para rede estadual e dummies de UF.

- Localização: dummy para capital e índice que capta o entorno escolar a partir de indicadores de violência contra a pessoa e contra o patrimônio, causados por agentes externos à escola.

- Recursos financeiros: índice com dummies para o recebimento de recursos de financiamento dos governos federal, estadual ou municipal e dummy para a insuficiência de recursos naquele ano.

- Complexidade da gestão: tamanho da escola (em número total de alunos) e dummy para o oferecimento de mais de uma etapa de ensino.

- Perfil dos gestores: formação acadêmica e experiência do diretor.

- Perfil dos docentes: formação acadêmica e experiência do professor.

- Tempo de dedicação do professor: índice com dummy para dedicação exclusiva à educação, dummy para dedicação exclusiva à escola, dummy para problema grave de rotatividade na escola.

- Composição do corpo discente: proporção de meninos na escola, proporção de alunos na escola que se declara de cor branca e proporção de alunos na escola que apresentam pelo menos um ano de atraso escolar.

- Nível socioeconômico dos alunos: índice com escolaridade da mãe (alfabetização e etapa da escolaridade concluída) e doze indicadores de renda (posse de bens duráveis e acesso a serviços).

- Manutenção e conservação da escola: índice que capta a conservação do prédio; índice que capta o ambiente físico das salas de aula.

- Equipamentos: índice que capta existência e condições de uso de quinze itens de equipamentos para uso administrativo (computador, impressora etc.).

- Espaços e recursos didático-pedagógicos: índice que capta existência e condições de uso de onze itens de espaços e equipamentos para uso pedagógico (biblioteca, laboratórios, computadores etc.); índice que capta tempo de uso do livro didático.

Já as dimensões de esforços são as seguintes:

- Espaços e recursos didático-pedagógicos: índice que capta intensidade de uso pelo professor na sala de aula de doze itens de recursos e materiais pedagógicos (livros, jornais, revistas, vídeos etc.).

\footnotetext{
${ }^{7}$ A Tabela A.1 apresenta a construção de cada variável/indicador.
} 
- Gestão pedagógica: dummy que indica se mais de $80 \%$ do currículo foi cumprido; índice que capta as práticas de ensino tradicionais (cópia, fixação, etc.); tamanho das turmas (número médio de alunos por turma); dummy que indica se a alocação de alunos nas turmas segue critérios de homogeneidade por idade ou rendimento; índice que capta uso do tempo escolar (falta de professores, absenteísmo docente e discente, problemas disciplinares).

- Gestão escolar: índice para a liderança do diretor (percepção dos professores); índice que capta planejamento escolar compartilhado, índice para o conhecimento dos dados das avaliações oficiais por parte dos professores; índice que capta participação dos professores nas decisões da escola e coesão do corpo docente; índice para expectativas dos professores quanto ao sucesso futuro dos alunos; índice para participação dos pais nos conselhos; índice que capta o clima escolar.

Em 2011, 4,2 milhões alunos em 55.707 escolas participaram do exame. Excluímos da amostra as 40 escolas federais $(0,07 \%)$, uma vez que essas apresentam modelos de gestão e processos de seleção de alunos bastante peculiares e distintos das demais escolas públicas. Também foram excluídas as 9.638 escolas rurais $(17,6 \%)$, já que os fatores contextuais que afetam estas unidades escolares (localidade, disponibilidade de recursos) também as tornam atípicas. Com isso, a amostra se reduz para 3,9 milhões de alunos (91\%) e 46.029 escolas $(82,7 \%)$.

Além disso, foram retiradas da amostra as escolas que apresentavam problemas relacionados ao não preenchimento dos questionários. Foram considerados alunos com respostas não válidas aqueles que deixaram de responder as informações de escolaridade da mãe ou que não responderam a mais de três dos doze itens que compõem o indicador de renda (194.137 estudantes). Excluíram-se as escolas em que mais de $10 \%$ dos alunos apresentaram respostas não válidas segundo esse critério. Nossa amostra final é composta por 44.721 escolas e 3.620.191 alunos (1.905.617 no $5^{\circ}$ ano e 1.714 .574 no $9^{\circ}$ ano do ensino fundamental).

As Tabelas 1 a 3 trazem as estatísticas descritivas da amostra final de escolas. A grande maioria das variáveis usadas são indicadores simples, cujos valores em si trazem pouco significado, mas que tem como principal atributo captar a variação de dimensões de difícil mensuração.

Nossa amostra contém $43 \%$ de escolas de redes estaduais e $17 \%$ localizadas em capitais. Em média, as escolas contam com 680 alunos matriculados, mas a variação é muito significativa (a menor escola tem 25 alunos e a maior mais de 7.000). O mesmo vale para o tamanho das turmas, que é de 26 alunos em média, mas chega a 84 nas maiores turmas.

O desempenho médio dos alunos do $5^{\circ}$ ano é de 187,9 pontos (Português) e 206,9 (Matemática), enquanto que para o $9^{\circ}$ ano a nota média é 238,9 (Português) e 245,6 (Matemática). O desvio-padrão das notas fica em torno de 20 pontos, em geral um pouco maior para o $5^{\circ}$ ano. Com relação ao perfil dos alunos, a amostra conta com escolas que têm, em média, $34 \%$ de estudantes que se declaram brancos e $21 \%$ em atraso escolar. 


\section{Resultados e Discussão}

As Tabelas 4 e 5 trazem as estimativas dos parâmetros das duas equações de interesse, uma que controla apenas as circunstâncias e outra que controla também os esforços. Os modelos foram estimados por MQO separadamente para o desempenho do $5^{\circ}$ e do $9^{\circ}$ ano em Língua Portuguesa e Matemática.

A grande maioria dos indicadores de circunstância se relaciona de forma significativa com o desempenho médio das escolas e essa significância, bem como a direção dos coeficientes, pouco mudam quando adicionamos as medidas de esforço. Isso pode indicar que a relação entre nossas medidas de esforços e de circunstâncias têm correlação fraca. Voltaremos a essa discussão mais à frente.

Em geral, os coeficientes dos indicadores de circunstâncias apontam na direção esperada, segundo a literatura. Em especial, as características médias dos estudantes têm alta correlação parcial com as notas. Escolas com maior porcentagem de alunos brancos e com maior nível socioeconômico têm notas mais altas, ceteris paribus, ao passo que escolas com maior porcentagem de alunos com atraso escolar e do gênero masculino têm notas menores. A correlação parcial entre gênero e notas é maior para a disciplina de português.

O perfil de experiência e escolaridade de professores e diretores parece ter relação positiva com as notas, exceto no caso da formação do diretor, que perde significância para algumas amostras. Já o conjunto de variáveis que captam os recursos físicos das escolas (pedagógicos, financeiros etc.) aparece ora com correlação significativa ora não significativa, a depender do modelo. Essa falta de robustez na correlação entre insumos e resultados escolares vai ao encontro do que a literatura já concluiu.

Entre as medidas de esforço, algumas se destacam com coeficientes significativos. Variáveis como cumprimento do currículo, uso de recursos pedagógicos e uso do tempo escolar (que inclui dedicação e rotatividade dos professores) são positivamente correlacionadas com as notas. $\mathrm{O}$ mesmo vale para o conhecimento dos professores sobre os resultados da Prova Brasil e suas expectativas sobre a progressão acadêmica de seus alunos.

A liderança do diretor é outra variável que merece destaque como positivamente correlacionada com o desempenho escolar, enquanto que as práticas de ensino tradicionais estão negativamente correlacionadas com as notas. Ambas as variáveis, apesar de pouco exploradas na literatura empírica, parecem apontar para a direção esperada pelo modelo conceitual que adotamos.

Quanto ao clima escolar e à participação dos professores nas decisões da escola, ambas não parecem apontar para a direção esperada, pois se correlacionam negativamente com o desempenho. No entanto, como esses dois indicadores dependem fortemente da percepção dos respondentes, é preciso interpretar a direção da correlação com cuidado. Essa correlação não esperada pode estar captando características não observáveis dos gestores. Pode-se supor que os melhores diretores, cujas escolas tenham notas médias mais elevadas, sejam mais críticos em relação ao baixo envolvimento dos pais nas atividades escolares, bem como ao relacionamento entre professores e alunos.

A partir dos parâmetros estimados, calculamos as notas contrafactuais e, com elas, a desigualdade devido às oportunidades. A primeira linha da Tabela 6 traz os índices $L$ de Theil calculados para cada amostra, que ficam pouco acima de 0,006 para os alunos do $5^{\circ}$ ano e de 0,003 para os estudantes do $9^{\circ}$ ano. As duas linhas seguintes trazem o mesmo índice, agora calculado sob a 
hipótese de que as escolas não se diferenciassem em termos das circunstâncias.

Ao equalizar as oportunidades entre as escolas, o $L$ de Theil do desempenho para alunos do $5^{\circ}$ ano cai para pouco mais de 0,002 . Com isso, calculamos que cerca de $60 \%$ da desigualdade de desempenho nessa série pode ser atribuída à desigualdade de oportunidades entre as escolas. Da mesma forma, estimamos que cerca de $55 \%$ da disparidade de notas para o $9^{\circ}$ ano está associada a desigualdade de oportunidades. Sendo assim, o efeito-escola corresponderia a algo em torno de $40 \%$ a $45 \%$ das diferenças observadas nas notas médias entre as escolas públicas brasileiras.

Comparando com outros trabalhos da literatura, nossas estimativas do efeito- escola são maiores. Artigos como Ferrão et al. (2001) e Felício \& Fernandes (2005) centram-se na estimação do efeito-escola e encontram resultados em torno de $30 \%$ a $35 \%$ para o $5^{\circ}$ ano do ensino fundamental, usando os dados do SAEB de 1999 e 2001, respectivamente. Uma possível explicação seria o aumento do efeito-escola ao longo dos anos. Por outro lado, o efeitoescola encontrado neste trabalho difere do restante da literatura do ponto de vista dos fatores que nele são incluídos. Em nossas estimativas, o efeito-escola corresponde apenas ao conjunto de fatores intraescolares sobre os quais os gestores das escolas exercem influência. Ou seja, excluímos dessa estimativa as variáveis relativas às escolas sobre as quais supostamente os diretores não possuem autonomia para modificar. Assim, dado que controlamos por um número maior de circunstâncias, esperaríamos encontrar um efeito-escola menor, o que não é o caso. Isso sugere que parte das circunstâncias dadas para as escolas atuam no sentido de elevar a desigualdade de notas.

Nossos resultados também diferem de trabalhos que se voltam mais ao cálculo das desigualdades de oportunidades, como Diaz (2012) - dados do SAEB para o ensino médio - e Procopio et al. (2015) - dados do Projeto Geres para o ensino fundamental -, que encontram efeitos das circunstâncias em torno de $10 \%$. Uma possível explicação para a diferença das estimativas é, além da própria diferença nas amostras, o fato de usarmos as escolas como unidades de análise. Essa escolha naturalmente reduz a variação de todos os fatores intraescolares, em especial as características dos alunos (que tem grande peso sobre as circunstâncias). Com isso, por um efeito estatístico, o peso das circunstâncias acaba se reduzindo.

Nesse sentido, nossos resultados também contribuem com um novo ponto de vista sobre a forma de calcular a desigualdade de oportunidades educacionais no Brasil. Ao usar as escolas como unidades de análise nossos cálculos se aproximam mais da dos gestores de rede, que enxerga as escolas como principais unidades de atuação.

Além disso, os resultados apontam para o maior peso das circunstâncias sobre a desigualdade de notas dos estudantes mais jovens, o que pode significar que o esforço é mais importante para explicar a dispersão de resultados à medida que os estudantes evoluem nos ciclos educacionais, ou seja, a escola deve exercer um efeito cumulativo sobre o desempenho.

As três últimas linhas da Tabela 6 trazem a separação entre os efeitos diretos e indiretos das circunstâncias sobre a desigualdade de desempenho escolar. Como podemos ver, a parcela da desigualdade devida a um efeito direto das oportunidades (isto é, após controlar pelas medidas de esforço) é praticamente igual ao efeito total. Dessa forma o efeito indireto das circunstâncias, que resulta da diferença entre os efeitos total e direto, é de apenas $0,5 \%$ ( $5^{\circ}$ 
ano) e $0,3 \%$ ( $9^{\circ}$ ano). Ou seja, levando-se em conta todas as circunstâncias em conjunto, os gestores teriam potencial para interferir sobre menos de $1 \%$ do total da contribuição da desigualdade de oportunidades para a iniquidade de notas. Esse efeito indireto quase nulo pode indicar que as circunstâncias operam apenas por canais diretos sobre a desigualdade de desempenho. Em outras palavras, as circunstâncias não teriam interação com as ações executadas pelas escolas e, portanto, a escola não conseguiria potencializar (ou amenizar) os efeitos benéficos (ou deletérios) do background familiar, por exemplo. Entretanto, é possível ainda que os efeitos indiretos de diferentes circunstâncias se anulem, se cada um operar sobre a desigualdade de notas em sentidos opostos. Mais adiante, apresentamos estimativas dos efeitos indiretos desagregados por circunstância.

Outra explicação adicional pode vir da qualidade das proxies de esforço consideradas nas estimações. Boa parte delas é baseada na percepção dos diretores e professores quanto ao bom funcionamento da escola, que pode estar negativamente correlacionada com sua capacidade de gestão administrativa e pedagógica. Nesse caso, as medidas de esforço observadas apresentariam menor dispersão do que as latentes.

De maneira geral, os resultados apontam que as escolas não teriam controle sobre uma parcela de $55-60 \%$ dos fatores que contribuem para equalizar o desempenho escolar. De fato, no contexto das escolas públicas brasileiras sabe-se que muitas das decisões, principalmente sobre alocação de recursos, são tomadas em instâncias superiores com pouca participação das escolas. Para lançar luz a essa questão, fizemos um exercício alternativo (Tabela 7), que consiste em estimar os efeitos da desigualdade de oportunidade para as redes de ensino. Isto é, repetimos os procedimentos equalizando agora fatores que são circunstanciais para as redes de ensino.

Alguns atributos considerados circunstanciais do ponto de vista das escolas passam a ser tratados como alvo do esforço dos secretários da educação. São variáveis que captam as seguintes dimensões descritas na Seção 3: leis e normas, localização, disponibilidade de recursos financeiros e equipamentos, complexidade da gestão, perfil dos gestores e perfil dos docentes. Com isso, pretende-se ampliar o escopo de análise levando em conta as possibilidades de ação das redes, o que corresponde a um cenário mais factível para a realidade dos sistemas educacionais públicos brasileiros.

A Tabela 7 mostra que a desigualdade de oportunidade para as redes de ensino responde por cerca de $40-50 \%$ da iniquidade de notas. A diferença encontrada entre o efeito da desigualdade de oportunidades para escolas e para redes (algo entre 11\% e 15\%) quantifica a capacidade de atuação das redes de ensino sobre as circunstâncias das escolas. Para exemplificar, considere o caso do desempenho em Matemática para o $5^{\circ}$ ano. Calculamos que cerca de $60 \%$ da desigualdade de notas deve-se a iniquidade de oportunidades para as escolas e $48 \%$ para as redes. Com isso, em torno de $12 \%(=60 \%-48 \%)$, ou seja, $1 / 5(=12 \% / 60 \%)$ daquilo que consideramos efeito da desigualdade de oportunidade para as escolas está, na verdade, sob o controle das redes de ensino. Nesse sentido, os resultados apontam para o potencial que políticas estabelecidas pelas redes (e que escapam do controle dos diretores) podem exercer sobre a desigualdade de notas entre as escolas, tais como qualidade do professor, capacidade administrativa dos diretores e dotação de insumos.

Da mesma forma que o exercício anterior, quase todo esse efeito se dá pela atuação direta (e não indireta) das circunstâncias sobre o desempenho escolar. 
Porém cabe destacar que, apesar de pequeno, o efeito indireto das circunstâncias para as redes é entre duas a cinco vezes maior que o efeito para as escolas. Isso pode ser explicado pelo fato de que a variação intrarredes do nível socioeconômico e da composição dos alunos é maior do que a variação intraescolar. Esse resultado sugere que as políticas educacionais estabelecidas pelas redes devam interagir com o perfil dos alunos atendidos pelas diferentes escolas.

Nesse conjunto de modelos estimados (apresentados nas Tabelas 4 e 5), o $R^{2}$ oscila entre 0,55 e 0,63 , o que indica que entre $37 \%$ e $45 \%$ da desigualdade de notas não é explicada pelo conjunto de variáveis incluídas nessa análise. No entanto, não há consenso na literatura se essa parcela da variância não explicada deve ser interpretada como circunstância ou esforço (ou nenhum deles). Mais do que isso, autores defendem que qualquer tentativa de endereçar o termo de erro das equações a um dos dois conjuntos de variáveis é uma decisão ad-hoc (Lefranc et al. 2008, 2009, Jusot et al. 2013).

As Tabelas 8 e 9 trazem um exercício que procura especificar qual o peso relativo de cada grupo de circunstâncias sobre os efeitos encontrados. Para isso, agrupamos as circunstâncias em quatro grandes grupos: alunos (inclui composição do corpo discente e NSE alunos); diretores e professores (engloba perfil dos gestores, perfil dos docentes, tempo de dedicação do professor); dotação de recursos (com recursos financeiros, manutenção e conservação da escola, espaços e disponibilidade de recursos didáticos, equipamentos) e contexto de gestão (inclui, complexidade de gestão, localização e tamanho das turmas).

Nesse caso, calculamos tanto o efeito direto como o indireto para cada grupo de circunstâncias. Como era de se esperar, a equalização do perfil dos alunos (nível socioeconômico e composição segundo idade, gênero e cor/raça) reduziria a desigualdade em uma faixa de 40-50\%. É interessante observar que parte significativa da contribuição do perfil dos estudantes para a desigualdade de notas advém do efeito indireto. No $5^{\circ}$ ano, estes são da ordem de $16 \%(8,2 \% / 49,7 \%)$ e $23 \%(10,6 \% / 46,1 \%)$, em português e matemática, respectivamente. Já no $9^{\circ}$ ano, são de $10 \%(4,3 \% / 41,1 \%)$ e $13 \%$ (5\%/38,6\%), também em português e matemática. Esses resultados mostram que, apesar de o perfil de alunos atendidos pelas escolas se colocarem como circunstâncias para elas, há ações ou políticas (esforços) que podem ser desenvolvidas pelos gestores das redes e das escolas que tem o potencial de amenizar os efeitos que as diferenças de perfil socioeconômico exercem sobre as desigualdades educacionais. Esses mecanismos de atuação dos gestores parecem ser mais efetivos na redução das desigualdades de notas de matemática e entre alunos mais novos ( $5^{\circ}$ ano). Embora possamos especular sobre quais seriam essas ações, identificálas está fora do escopo deste trabalho.

Outro resultado interessante refere-se à equalização dos recursos físicos (prédio escolar, equipamentos, recursos didático-pedagógicos) ou dos recursos humanos (formação, experiência e dedicação de diretores e professores) entre as escolas. Caso todas as escolas contassem com diretores e professores com a mesma formação e o mesmo tempo de experiência, a desigualdade das notas se reduziria em apenas 3\%. Entretanto, a contribuição do perfil dos gestores e docentes para reduzir a desigualdade de desempenho advém exclusivamente do esforço, uma vez que o efeito direto dessa equalização contribuiria para elevar a desigualdade.

Em outras palavras, políticas que atuem sobre a melhoria de qualidade dos professores e/ou de capacitação dos gestores só são efetivas em reduzir a desi- 
gualdade por meio de medidas de esforços das escolas. Por exemplo, é possível que melhores professores exijam maior participação no planejamento escolar, demandem mais autonomia para a escolha de materiais e práticas didáticas etc. Então, a melhoria da qualidade do professor que não fosse acompanhada de mudanças nessas dimensões complementares poderia beneficiar mais as melhores escolas do que as piores.

As mesmas conclusões se aplicam ao caso da dotação de recursos, cuja equalização só afeta a redução de desigualdade por meio do canal indireto, ou seja, de sua interação com os esforços das redes e das escolas. Ou seja, a maior disponibilidade de espaços e recursos pedagógicos (biblioteca, laboratórios, computadores) só deve reduzir a desigualdade caso estes sejam efetivamente utilizados por meio de práticas pedagógicas adequadas. Por exemplo, caso todas as escolas dispusessem de laboratórios de informática com computadores para uso dos alunos, mas diferissem quanto às atividades desenvolvidas com esses recursos (atividades didáticas e de lazer), isso poderia se refletir em aumento da desigualdade. Note que a equalização de recursos tem maior potencial de reduzir as desigualdades entre os alunos do $5^{\circ}$ ano (em torno de $5 \%$ ) do que entre os estudantes do $9^{\circ}$ ano $(3,3 \%)$.

Por fim, estão os resultados da equalização do contexto de gestão, que inclui as normas de cada rede de ensino (captadas por dummies de UF e dependência administrativa), a localização (medida por um índice de violência do entorno), a complexidade de gestão (tamanho da escola e oferecimento de diferentes etapas de ensino) e o tamanho das turmas. Nesse caso, os resultados para o $5^{\circ}$ e o $9^{\circ}$ anos são qualitativamente distintos. A equalização dessas variáveis reduziria a desigualdade de notas entre os alunos mais novos (entre $11 \%$ e $18 \%$, em português e matemática), mas a elevaria entre os alunos mais velhos (em pouco mais de $7 \%$ ).

Para o caso do $5^{\circ}$ ano, praticamente metade dessa equalização atua por meio da interação com os esforços. O mesmo não se aplica ao $9^{\circ}$ ano, para o qual essa dimensão exerce praticamente apenas efeitos diretos. Para interpretar melhor esses resultados, analisamos isoladamente o peso de cada circunstância que compõe essa dimensão. Os resultados encontram-se na Tabela 10.

Como esperado, a equalização do entorno escolar, do tamanho da escola e das turmas e do número de etapas de ensino oferecidas pela escola atuariam no sentido de reduzir a desigualdade, inclusive no $9^{\circ}$ ano. Inclusive, esses efeitos são ainda maiores no $9^{\circ}$ do que no $5^{\circ}$ ano, o que é intuitivo. Assim, o efeito direto negativo da dimensão contexto de gestão observado para o $9^{\circ}$ ano advém inteiramente das variáveis incluídas em leis e normas, que captam as diferentes redes de ensino (redes municipais e estaduais de cada Unidade da Federação). O que pode estar por trás desse resultado, por exemplo, são as diferenças nos parâmetros curriculares mínimos, de políticas de progressão continuada e outras especificidades das redes. O que nossos resultados estão sugerindo é que a equalização dessas diferenças geraria efeitos deletérios sobre o aumento da desigualdade entre alunos mais avançados na educação básica. Por exemplo, pode-se considerar que a heterogeneidade dos parâmetros curriculares é maior no final do que no início do ensino fundamental. Assim, o estabelecimento de um currículo único poderia aumentar ainda mais a distância das notas entre os alunos com menor e maior desempenho.

É importante ressaltar que os exercícios empíricos realizados neste artigo não têm como objetivo estabelecer relações de causalidade e, por esse motivo, 
não são empregados tratamentos econométricos que procurem lidar adequadamente com possíveis vieses de omissão de variáveis. De todo modo, cabe pontuar de que maneira a omissão de variáveis pode afetar os resultados encontrados. Segundo Roemer (1998), a preocupação é maior quando o termo não observado pertence a um grupo (circunstância ou esforço) e a variável incluída no modelo pertence a outro. Se, por exemplo, uma variável de esforço relevante não observada for correlacionada positivamente com uma variável de circunstância incluída no modelo, então este resultará em estimativas do limite superior do peso das circunstâncias. Em nosso caso, isso implicaria subestimar o poder das ações dos diretores ou da rede na redução das desigualdades educacionais. Ao considerar um modelo teórico educacional que contempla diferentes dimensões determinantes do aprendizado e ao utilizar uma base de dados tão rica quanto a Prova Brasil na tentativa de abordar essas dimensões, acreditamos que essa questão não seja tão relevante.

Além disso, o viés produzido pela omissão de variáveis relevantes correlacionadas com variáveis incluídas pertencentes ao mesmo grupo (circunstância ou esforço) não deve ser uma questão tão preocupante. Isso porque os objetos de análise não são os coeficientes per se, mas sim a contribuição agregada de um conjunto de fatores que se coloca como circunstâncias ou esforços. Assim, o viés acaba por incorporar o efeito de uma variável que gostaríamos de observar quando estimamos a contribuição relativa das circunstâncias e dos esforços.

\section{Comentários Finais}

O presente artigo contribui para a literatura de desigualdades de oportunidades educacionais e efeito-escola, adotando abordagens conceitual e empírica alternativas.

A literatura tradicionalmente separa os determinantes do aprendizado entre fatores extra e intraescolares. Isso pressupõe que os diretores das escolas têm controle sobre todos os insumos escolares, o que não reflete a realidade das escolas públicas brasileiras, cujos gestores possuem baixa autonomia. A primeira contribuição do artigo é separar os determinantes do aprendizado entre circunstâncias e esforços. Por circunstância, entende-se qualquer fator que não pode ser modificado pela escola. Já nos esforços incluem-se todas as ações das escolas ou políticas educacionais estabelecidas pelas redes que podem afetar o desempenho, com o olhar sobre a capacidade de atuação dos gestores das redes de ensino e das escolas. A estratégia empírica adotada também permite distinguir entre os efeitos direto e indireto da desigualdade de oportunidades. Os esforços são considerados endógenos e, portanto, são afetados pelas circunstâncias. Assim, o efeito indireto estima em que medida as circunstâncias afetam a desigualdade de notas por meio de sua interação com os esforços dos gestores.

Para as redes, consideramos como circunstâncias a composição e o nível socioeconômico dos alunos. Para as escolas, somam-se a esses fatores de circunstâncias os contextos específicos de gestão (leis e normas da rede de ensino, localização, tamanho da escola, tamanho das turmas e oferecimento de mais de uma etapa de ensino), a dotação de recursos (recursos financeiros, prédio escolar, equipamentos, espaços e recursos didático-pedagógicos), o perfil dos gestores e professores (formação e experiência) e o tempo de dedicação dos 
professores à escola. O efeito-rede é da ordem de $50 \%$ a $60 \%$, enquanto que o efeito-escola foi estimado em cerca de $40 \%$ a $45 \%$. Isso mostra que entre $10 \%$ e $15 \%$ da desigualdade de notas está sob controle de políticas educacionais estabelecidas pelos órgãos centrais, mas fogem ao controle direto dos diretores das escolas. Esses efeitos sugerem que a baixa autonomia das escolas limita suas possibilidades de reduzir as iniquidades educacionais. Esse resultado pode contribuir, por exemplo, para a discussão dos impactos potenciais de políticas de accountability.

Embora o nível socioeconômico e a composição dos estudantes sejam as circunstâncias mais importantes para explicar a desigualdade de notas, entre $10 \%$ e $23 \%$ da contribuição do perfil dos alunos exercem efeito indireto sobre essa desigualdade e, portanto, seus efeitos podem ser influenciados por políticas educacionais ou ações das escolas. As estimativas dos efeitos indiretos ainda sugerem outras conclusões interessantes. A redução da desigualdade de notas por meio da equalização dos recursos físicos ou da qualidade dos professores e gestores exige a implantação de políticas educacionais complementares, que se referem a esforços das escolas. Isso porque o efeito direto dessas circunstâncias é negativo, mas o efeito indireto é positivo. Além disso, o efeito das especificidades das redes de ensino, que podem refletir diferenças nos parâmetros curriculares mínimos ou de políticas de progressão continuada, atua no sentido de reduzir a desigualdade das notas no $5^{\circ}$ ano, mas de aumentá-la no $9^{\circ}$ ano. Assim, conjuntamente, nossas estimativas mostram a importância que as interações entre circunstâncias e esforços exercem sobre a desigualdade de resultados educacionais e podem sinalizar para a necessidade de que as políticas educacionais se ajustem às especificidades de diferentes tipos de escolas.

\section{Referências Bibliográficas}

Aaronson, D., Barrow, L. \& Sander, W. (2007), 'Teachers and student achievement in the Chicago public high schools', Journal of Labor Economics 25(1), 95-135.

Albernaz, A., Ferreira, F. \& Franco, C. (2002), 'Qualidade e equidade na educação fundamental brasileira', Departamento de Economia - PUC-RJ .

Alves, F. (2008), 'Políticas educacionais e desempenho escolar nas capitais brasileiras', Cadernos de Pesquisa 38(134), 413-440.

Andrade, R. \& Soares, J. (2008), 'O efeito da escola básica brasileira', Estudos em Avaliação Educacional 19(41), 379-406.

Barros, R., Mendonça, R., Santos, D. \& Quintaes, G. (2001), 'Determinantes do desempenho educacional no Brasil', Pesquisa e Planejamento Econômico 31(1), 1-42.

Betts, J. (1996), 'Do school resources matter only for older workers?', Review of Economics and Statistics 78(4), 638-652.

Bourguignon, F., Ferreira, F. \& Menendez, M. (2007), 'Inequality of opportunity in Brazil', Review of Income and Wealth 53(4), 585-618. 
Brooke, N. \& Soares, J. (2011), 'Pesquisa em eficácia escolar: origem e trajetória', Estudos em Avaliação Educacional 22(50), 593-598.

Buddin, R. \& Zamarro, G. (2009), 'Teacher qualifications and student achievement in urban elementary schools', Journal of Urban Economics 66(2), 103115.

Cohen, D., Raudenbush, D. \& Ball, D. (2002), Resources, instruction and research, in Mosteller, F. E. Boruch, R. (Org.), Evidence Matters: Randomized Trials in Education Research, 1 edn, Brookings Institution Press.

Coleman, J. S. (1966), Equality of Educational Opportunity, 1 edn, U.S. Department of Health, Education, and Welfare, Office of Education.

Diaz, M. (2012), '(Des) Igualdades de oportunidades no ensino médio brasileiro: escolas públicas e privadas', Economia 13(3a), 553-568.

Felício, F. \& Fernandes, R. (2005), 'Os efeitos da qualidade da escola sobre o desempenho escolar: uma avaliação do ensino fundamental no estado de São Paulo', XXXIII Encontro Nacional de Economia - ANPEC.

Ferreira, F. H. G. \& Gignoux, J. (2008), 'The measurement of inequality of opportunity: theory and an application to Latin America', The World Bank. Policy Research Working Papers 4659.

Ferrão, M. E., Beltrão, K. I., Fernandes, C., Santos, D., Suarez, M. \& Andrade, A. C. (2001), 'O SAEB - Sistema Nacional de Avaliação da Educação Básica: objetivos, características e contribuições na investigação da escola eficaz', $R e$ vista Brasileira de Estudos de População 18(1/2), 111-130.

Gibbons, S. \& McNally, S. (2013), 'The effects of resources across school phases: a summary of ecente evidence', Center for Economic Performance. Discussion Paper $n^{\circ} 1.226$.

Glewee, P. W., Hanushek, E. A., Humpage, S. D. \& Ravina, R. (2011), 'School resources and educational outcomes in developing countries: a review of the literature from 1990 to 2010', National Bureau of Economic Research. Working Paper 17.554.

Hanushek, E. (1986), 'The economics of schooling: production and efficiency in public schools', Journal of Economic Literature 24(3), 1141-1177.

Hanushek, E. \& Luque, J. (2003), 'Efficiency and equity in schools around the world', Economics of Education Review 22(5), 481-502.

Heckman, J., Layne-Farrar, A. \& Todd, P. (1996), 'Human capital pricing equations with an application to estimating the effect of schooling quality on earnings', The Review of Economics and Statistics 78(4), 562-610.

Jusot, F., Tubeuf, S. \& Trannoy, A. (2013), 'Circumstances and efforts: how important is their correlation for the measurement of inequality of opportunity in health?', Health Economics 22(12), 1470-1495.

Lee, V. (2010), 'A necessidade dos dados longitudinais na identificação do efeito-escola', Revista Brasileira de Estudos Pedagógicos 91(229), 471-480. 
Lee, V. E., Bryk, A. S. \& Smith, J. B. (1993), 'The organization of effective secondary schools', Review of Research in Education 19, 171-267.

Lefranc, A., Pistolesi, N. \& Trannoy, A. (2008), 'Inequality of opportunities vs. inequality of outcomes: are western societies all alike?', Review Income and Wealth 54(4), 513-546.

Lefranc, A., Pistolesi, N. \& Trannoy, A. (2009), 'Equality of opportunity and luck: definitions and testable conditions, with an application to income in France', Journal of Public Economics 93(11-12), 1189-1207.

Procopio, I., Freguglia, R. \& Chein, F. (2015), 'Desigualdade de oportunidades na formação de habilidades: uma análise com dados longitudinais', Economia Aplicada 19(2), 326-348.

Rivkin, S., Hanushek, E. \& Kain, J. (2005), 'Teachers, schools, and academic achievement', Econometrica 73(2), 417-458.

Rockoff, J. (2004), 'The impact of individual teachers on student achievement: evidence from panel data', The American Economic Review 94(2), 247252.

Roemer, J. (1998), Equality of Opportunity, 1 edn, Harvard University Press.

Scheerens, J. \& Bosker, R. (1997), The Foundations of Educational Effectiveness, 1 edn, Pergamon, Oxford.

Soares, J. (2007), 'Melhoria do desempenho cognitivo dos alunos do ensino fundamental', Cadernos de Pesquisa 37, 135-160. 
Tabela 1: Estatísticas descritivas - desempenho

\begin{tabular}{lrrrrr}
\hline Variável & \multicolumn{5}{c}{ Escolas Média Desvio Padrão Mínimo Máximo } \\
\hline Nota Língua Portuguesa da Escola - 50 ano & 32,141 & 187,93 & 20,71 & 118,03 & 289,46 \\
Nota Língua Portuguesa da Escola - 9 $9^{\circ}$ ano & 25,318 & 238,96 & 18,49 & 152,94 & 321,46 \\
Nota Matemática da Escola - 5 ${ }^{\circ}$ ano & 32,141 & 206,99 & 24,42 & 132,38 & 314,46 \\
Nota Matemática da Escola - $9^{\circ}$ ano & 25,318 & 245,65 & 20,89 & 157,43 & 351,87 \\
\hline
\end{tabular}

Fonte: Prova Brasil 2011.

Tabela 2: Estatísticas descritivas - circunstâncias

\begin{tabular}{|c|c|c|c|c|c|}
\hline \multirow{2}{*}{$\frac{\text { Variável }}{\text { Leis e normas }}$} & \multicolumn{5}{|c|}{ Escolas Média Desvio PadrãoMínimo Máximo } \\
\hline & & & & & \\
\hline Escolas de rede estadual (dummy) & 44,722 & 0,430 & 0,500 & 0,000 & 1,000 \\
\hline $\begin{array}{l}\text { Localização da escola } \\
\text { Escolas em capitais (dummy) } \\
\text { Entorno escolar (indicador) }\end{array}$ & $\begin{array}{l}44,722 \\
44,516\end{array}$ & $\begin{array}{l}0,170 \\
2,750\end{array}$ & $\begin{array}{l}0,370 \\
3,090\end{array}$ & $\begin{array}{l}0,000 \\
0,000\end{array}$ & $\begin{array}{r}1,000 \\
19,000\end{array}$ \\
\hline Recursos financeiros (indicador) & 44,609 & 2,330 & 0,850 & 0,000 & 4,000 \\
\hline $\begin{array}{l}\text { Complexidade da gestão } \\
\text { Escolas que oferecem múltiplas etapas }(\text { dummy) } \\
\text { Número total de matrículas } \\
\text { Tamanho médio das turmas }\end{array}$ & $\begin{array}{l}44,722 \\
44,722 \\
44,722\end{array}$ & $\begin{array}{r}0,530 \\
680,800 \\
26,020\end{array}$ & $\begin{array}{r}0,500 \\
442,480 \\
5,990\end{array}$ & $\begin{array}{r}0,000 \\
25,000 \\
4,800\end{array}$ & $\begin{array}{r}1,000 \\
474,000 \\
84,640\end{array}$ \\
\hline $\begin{array}{l}\text { Perfil dos gestores } \\
\text { Formação (dummy pós-graduação em gestão) } \\
\text { Experiência do diretor (dummy mais de } 5 \text { anos) }\end{array}$ & $\begin{array}{l}43,527 \\
44,086\end{array}$ & $\begin{array}{l}0,370 \\
0,480\end{array}$ & $\begin{array}{l}0,480 \\
0,500\end{array}$ & $\begin{array}{l}0,000 \\
0,000\end{array}$ & $\begin{array}{l}1,000 \\
1,000\end{array}$ \\
\hline $\begin{array}{l}\text { Perfil dos professores } \\
\text { Formação acadêmica do professor (indicador) } \\
\text { Experiência do professor (indicador) }\end{array}$ & $\begin{array}{l}44,631 \\
44,648\end{array}$ & $\begin{array}{l}1,440 \\
0,950\end{array}$ & $\begin{array}{l}0,460 \\
0,590\end{array}$ & $\begin{array}{l}0,000 \\
0,000\end{array}$ & $\begin{array}{l}2,000 \\
2,000\end{array}$ \\
\hline $\begin{array}{l}\text { Dedicação do professor (dummy leciona em uma } \\
\text { escola) }\end{array}$ & 44,718 & 0,500 & 0,260 & 0,000 & 1,000 \\
\hline $\begin{array}{l}\text { Composição do corpo discente } \\
\text { Gênero dos alunos (dummy meninos) } \\
\text { Raça dos alunos (dummy brancos) } \\
\text { Atraso escolar (dummy atrasados) }\end{array}$ & $\begin{array}{l}44,722 \\
44,722 \\
44,722\end{array}$ & $\begin{array}{l}0,490 \\
0,340 \\
0,210\end{array}$ & $\begin{array}{l}0,080 \\
0,180 \\
0,140\end{array}$ & $\begin{array}{l}0,000 \\
0,000 \\
0,000\end{array}$ & $\begin{array}{l}1,000 \\
1,000 \\
1,000\end{array}$ \\
\hline Nível socioeconômico dos alunos (indicador) & 44,722 & 14,480 & 2,280 & 6,210 & 23,610 \\
\hline $\begin{array}{l}\text { Manutenção e conservação da escola } \\
\text { Conservação do prédio escolar (indicador) } \\
\text { Ambiente físico das salas de aula (indicador) }\end{array}$ & $\begin{array}{l}44,660 \\
39,591\end{array}$ & $\begin{array}{l}2,030 \\
1,750\end{array}$ & $\begin{array}{l}1,580 \\
0,550\end{array}$ & $\begin{array}{l}0,000 \\
0,000\end{array}$ & $\begin{array}{l}4,000 \\
2,000\end{array}$ \\
\hline Equipamentos (indicador) & 44,545 & 9,520 & 3,700 & 0,000 & 15,000 \\
\hline $\begin{array}{l}\text { Espaço e recursos didático-pedagógicos } \\
\text { Existência de recursos pedagógicos (indicador) } \\
\text { Livro didático (indicador) }\end{array}$ & $\begin{array}{l}44,555 \\
43,917\end{array}$ & $\begin{array}{l}4,290 \\
1,180\end{array}$ & $\begin{array}{l}2,510 \\
0,670\end{array}$ & $\begin{array}{l}0,000 \\
0,000\end{array}$ & $\begin{array}{r}11,000 \\
2,000\end{array}$ \\
\hline
\end{tabular}

Fonte: Prova Brasil e Censo Escolar 2011. 
Tabela 3: Estatísticas descritivas - esforços

\begin{tabular}{|c|c|c|c|c|c|}
\hline Variável & Escolas & Média & Desvio Padrão & Mínimo & Máximo \\
\hline $\begin{array}{l}\text { Espaço e recursos didático-pedagógicos } \\
\text { Uso de recursos pedagógicos (indicador) }\end{array}$ & 44,698 & 7,89 & 1,79 & 0,00 & 11,00 \\
\hline $\begin{array}{l}\text { Gestão pedagógica } \\
\text { Práticas de ensino tradicionais (indica- } \\
\text { dor) }\end{array}$ & 44,574 & 6,61 & 2,30 & 0,00 & 18,00 \\
\hline $\begin{array}{l}\text { Cumprimento curricular (dummy mais } \\
\text { de } 80 \% \text { cumprido) }\end{array}$ & 44,574 & 0,39 & 0,36 & 0,00 & 1,00 \\
\hline $\begin{array}{l}\text { Alocação das turmas (dummy alocação } \\
\text { idade ou renda) }\end{array}$ & 43,926 & 0,47 & 0,50 & 0,00 & 1,00 \\
\hline Uso do tempo escolar (indicador) & 44,716 & 0,84 & 0,40 & 0,00 & 3,00 \\
\hline Gestão escolar & & & & & \\
\hline Liderança do diretor (indicador) & 44,664 & 4,11 & 2,66 & 0,00 & 9,00 \\
\hline $\begin{array}{l}\text { Planejamento (dummy envolvimento do } \\
\text { professor em elaborar projetos pedagógi- } \\
\text { cos) }\end{array}$ & 44,327 & 0,63 & 0,33 & 0,00 & 1,00 \\
\hline $\begin{array}{l}\text { Conhecimento resultados avaliações (in- } \\
\text { dicador) }\end{array}$ & 44,722 & 2,26 & 0,77 & 0,00 & 3,00 \\
\hline $\begin{array}{l}\text { Participação dos professores nas deci- } \\
\text { sões da escola (indicador) }\end{array}$ & 44,648 & 2,34 & 1,62 & 0,00 & 6,00 \\
\hline $\begin{array}{l}\text { Expectativas de sucesso escolar (indica- } \\
\text { dor) }\end{array}$ & 44,122 & 0,85 & 0,61 & 0,00 & 2,00 \\
\hline Participação dos pais (indicador) & 44,384 & 1,60 & 0,65 & 0,00 & 2,00 \\
\hline Clima escolar (indicador) & 44,649 & 2,86 & 2,07 & 0,00 & 21,00 \\
\hline
\end{tabular}

Fonte: Prova Brasil e Censo Escolar 2011. 
Tabela 4: Estimativas dos modelos que relacionam notas, circunstâncias e esforços - escolas com $5^{\circ}$ ano

\begin{tabular}{|c|c|c|c|c|}
\hline & \multicolumn{2}{|c|}{ Língua Portuguesa } & \multicolumn{2}{|c|}{ Matemática } \\
\hline & $\mathrm{C}$ & $\mathbf{C}+\mathbf{E}$ & C & $\mathbf{C}+\mathbf{E}$ \\
\hline Rede estadual & $\begin{array}{c}-1,888^{* * *} \\
(0,205)\end{array}$ & $\begin{array}{c}-2,413^{* * *} \\
(0,206)\end{array}$ & $\begin{array}{c}-1,654^{* * *} \\
(0,244)\end{array}$ & $\begin{array}{c}-2,247^{* * * *} \\
(0,244)\end{array}$ \\
\hline Capital & $\begin{array}{c}-1,503^{* * * *} \\
(0,231)\end{array}$ & $\begin{array}{c}-0,671^{* * *} \\
(0,229)\end{array}$ & $\begin{array}{c}-3,070^{* * *} \\
(0,274)\end{array}$ & $\begin{array}{c}-1,978^{* * * *} \\
(0,271)\end{array}$ \\
\hline Entorno escolar & $\begin{array}{c}-0,364^{* * * *} \\
(0,030)\end{array}$ & $\begin{array}{c}-0,247^{* * *} \\
(0,029)\end{array}$ & $\begin{array}{c}-0,480^{* * *} \\
(0,036)\end{array}$ & $\begin{array}{c}-0,328^{* * * *} \\
(0,035)\end{array}$ \\
\hline Recursos financeiros & $\begin{array}{l}0,186^{*} \\
(0,097)\end{array}$ & $\begin{array}{l}0,091 \\
(0,096)\end{array}$ & $\begin{array}{l}0,458^{* * *} \\
(0,118)\end{array}$ & $\begin{array}{c}0,354^{* * *} \\
(0,117)\end{array}$ \\
\hline Múltiplas etapas & $\begin{array}{l}0,251 \\
(0,172)\end{array}$ & $\begin{array}{l}0,196 \\
(0,170)\end{array}$ & $\begin{array}{c}0,400^{*} \\
(0,209)\end{array}$ & $\begin{array}{c}0,374^{*} \\
(0,207)\end{array}$ \\
\hline Número total de matrículas & $\begin{array}{c}-0,004^{* * *} \\
(0,000)\end{array}$ & $\begin{array}{c}-0,003^{* * *} \\
(0,000)\end{array}$ & $\begin{array}{c}-0,004^{* * *} \\
(0,000)\end{array}$ & $\begin{array}{c}-0,003^{* * *} \\
(0,000)\end{array}$ \\
\hline Tamanho das turmas & $\begin{array}{l}0,050^{* *} \\
(0,020)\end{array}$ & $\begin{array}{l}0,055^{\text {*** }} \\
(0,020)\end{array}$ & $\begin{array}{r}-0,009 \\
(0,024)\end{array}$ & $\begin{array}{r}-0,006 \\
(0,025)\end{array}$ \\
\hline Formação acadêmica do diretor & $\begin{array}{l}0,346^{* *} \\
(0,174)\end{array}$ & $\begin{array}{l}0,208 \\
(0,173)\end{array}$ & $\begin{array}{c}0,270 \\
(0,212)\end{array}$ & $\begin{array}{c}0,097 \\
(0,210)\end{array}$ \\
\hline Experiência do diretor & $\begin{array}{l}0,860^{* * *} \\
(0,167)\end{array}$ & $\begin{array}{l}0,618^{* * *} \\
(0,166)\end{array}$ & $\begin{array}{l}1,137^{* * *} \\
(0,203)\end{array}$ & $\begin{array}{l}0,830^{* * *} \\
(0,202)\end{array}$ \\
\hline Formação acadêmica do professor & $\begin{array}{l}1,840^{* * * *} \\
(0,177)\end{array}$ & $\begin{array}{l}1,222^{* * *} \\
(0,181)\end{array}$ & $\begin{array}{l}2,425^{* * *} \\
(0,213)\end{array}$ & $\begin{array}{l}1,759^{* * *} \\
(0,217)\end{array}$ \\
\hline Experiência do professor & $\begin{array}{l}0,615^{* * *} \\
(0,127)\end{array}$ & $\begin{array}{l}0,329^{* * *} \\
(0,130)\end{array}$ & $\begin{array}{l}1,188^{* * *} \\
(0,155)\end{array}$ & $\begin{array}{l}0,849^{* * * *} \\
(0,158)\end{array}$ \\
\hline Tempo de dedicação do professor & $\begin{array}{l}0,627^{* *} \\
(0,305)\end{array}$ & $\begin{array}{l}0,915^{* * *} \\
(0,306)\end{array}$ & $\begin{array}{l}0,958^{* * *} \\
(0,369)\end{array}$ & $\begin{array}{l}1,426^{* * *} \\
(0,370)\end{array}$ \\
\hline Gênero dos alunos e (proporção de meninos) & $\begin{array}{c}-18,590^{* * * *} \\
(1,031)\end{array}$ & $\begin{array}{c}-18,171^{* * * *} \\
(1,034)\end{array}$ & $\begin{array}{c}-3,460^{* * *} \\
(1,235)\end{array}$ & $\begin{array}{c}-3,142^{* *} \\
(1,235)\end{array}$ \\
\hline Raça dos alunos e (proporção de brancos) & $\begin{array}{l}9,632^{* * *} \\
(0,715)\end{array}$ & $\begin{array}{l}8,435^{* * * *} \\
(0,714)\end{array}$ & $\begin{array}{c}13,936^{* * *} \\
(0,880)\end{array}$ & $\begin{array}{c}12,450^{* * *} \\
(0,879)\end{array}$ \\
\hline Atraso escolar & $\begin{array}{c}-24,202^{* * *} \\
(0,800)\end{array}$ & $\begin{array}{c}-19,106^{* * *} \\
(0,820)\end{array}$ & $\begin{array}{c}-25,768^{* * *} \\
(0,977)\end{array}$ & $\begin{array}{c}-19,353^{* * * *} \\
(0,998)\end{array}$ \\
\hline Nível socioeconômico dos alunos & $\begin{array}{l}5,029^{* * *} \\
(0,063)\end{array}$ & $\begin{array}{l}4,671^{* * *} \\
(0,064)\end{array}$ & $\begin{array}{l}5,067^{* * *} \\
(0,077)\end{array}$ & $\begin{array}{l}4,628^{* * *} \\
(0,078)\end{array}$ \\
\hline Conservação do prédio escolar & $\begin{array}{l}0,190^{* * *} \\
(0,061)\end{array}$ & $\begin{array}{l}0,103^{*} \\
(0,060)\end{array}$ & $\begin{array}{l}0,222^{* * *} \\
(0,074)\end{array}$ & $\begin{array}{l}0,116 \\
(0,073)\end{array}$ \\
\hline Ambiente físico das salas de aula & $\begin{array}{l}0,320^{* *} \\
(0,160)\end{array}$ & $\begin{array}{l}0,336^{* *} \\
(0,160)\end{array}$ & $\begin{array}{l}0,533^{* * *} \\
(0,190)\end{array}$ & $\begin{array}{l}0,524^{* * *} \\
(0,191)\end{array}$ \\
\hline Equipamentos & $\begin{array}{l}0,171^{* * *} \\
(0,031)\end{array}$ & $\begin{array}{l}0,104^{* * *} \\
(0,031)\end{array}$ & $\begin{array}{l}0,211^{* * *} \\
(0,037)\end{array}$ & $\begin{array}{l}0,129^{* * *} \\
(0,037)\end{array}$ \\
\hline Espaço e recursos didático-pedagógicos & $\begin{array}{l}0,119^{* * *} \\
(0,045)\end{array}$ & $\begin{array}{l}0,058 \\
(0,045)\end{array}$ & $\begin{array}{l}0,169^{* * *} \\
(0,056)\end{array}$ & $\begin{array}{l}0,089 \\
(0,055)\end{array}$ \\
\hline Livro didático & $\begin{array}{l}0,029 \\
(0,124)\end{array}$ & $\begin{array}{r}-0,083 \\
(0,123)\end{array}$ & $\begin{array}{l}0,448^{* * *} \\
(0,151)\end{array}$ & $\begin{array}{l}0,269^{*} \\
(0,149)\end{array}$ \\
\hline Uso de recursos pedagógicos & - & $\begin{array}{l}0,473^{\text {****}} \\
(0,054)\end{array}$ & - & $\begin{array}{l}0,615^{\text {***}} \\
(0,065)\end{array}$ \\
\hline Práticas de ensino tradicionais & - & $\begin{array}{c}-0,331^{* * *} \\
(0,035)\end{array}$ & - & $\begin{array}{c}-0,394^{* * *} \\
(0,042)\end{array}$ \\
\hline Cumprimento curricular & - & $\begin{array}{l}5,034^{* * *} \\
(0,230)\end{array}$ & - & $\begin{array}{l}7,080^{* * *} \\
(0,281)\end{array}$ \\
\hline Alocação dos alunos nas turmas & - & $\begin{array}{l}0,079 \\
(0,165)\end{array}$ & - & $\begin{array}{l}0,231 \\
(0,199)\end{array}$ \\
\hline Uso do tempo escolar & - & $\begin{array}{l}1,613^{* * *} \\
0,230)\end{array}$ & - & $\begin{array}{l}2,509^{* * * *} \\
(0,281)\end{array}$ \\
\hline Liderança do diretor & - & $\begin{array}{l}0,126^{* * *} \\
(0,041)\end{array}$ & - & $\begin{array}{l}0,181^{* * *} \\
(0,050)\end{array}$ \\
\hline Planejamento escolar & - & $\begin{array}{l}0,003 \\
(0,239)\end{array}$ & - & $\begin{array}{l}0,050 \\
(0,292)\end{array}$ \\
\hline Conhecimento das avaliações & - & $\begin{array}{l}1,299^{* * *} \\
(0,110)\end{array}$ & - & $\begin{array}{l}1,578^{* * *} \\
(0,129)\end{array}$ \\
\hline $\begin{array}{l}\text { Participação dos professores nas decisões da } \\
\text { escola }\end{array}$ & - & $\begin{array}{c}-0,210^{* * *} \\
(0,067)\end{array}$ & - & $\begin{array}{c}-0,238^{* * *} \\
(0,081)\end{array}$ \\
\hline Expectativas de sucesso escolar & - & $\begin{array}{l}1,771^{* * *} \\
(0,132)\end{array}$ & - & $\begin{array}{l}1,757^{* * * *} \\
(0,160)\end{array}$ \\
\hline
\end{tabular}

Fonte: Prova Brasil e Censo Escolar 2011. Elaboração própria. Nota: Erros-padrão entre parênteses. 
Tabela 4: Estimativas dos modelos que relacionam notas, circunstâncias e esforços - escolas com $5^{\circ}$ ano (continuação)

\begin{tabular}{lcccc}
\hline & \multicolumn{2}{c}{ Língua Portuguesa } & \multicolumn{2}{c}{ Matemática } \\
& C & C+E & C & C+E \\
\hline Participação dos pais & - & $-0,093$ & - & $-0,107$ \\
& & $(0,132)$ & & $(0,160)$ \\
Clima escolar & - & $-0,301^{* * *}$ & - & $-0,318^{* * *}$ \\
& & $(0,040)$ & & $(0,049)$ \\
Dummies de UF & Sim & Sim & Sim & Sim \\
Constante & $124,125^{* * *}$ & $121,400^{* * *}$ & $132,844^{* * *}$ & $128,344^{* * *}$ \\
Número de Observações & $(1,384)$ & $(1,483)$ & $(1,648)$ & $(1,773)$ \\
R2 & 26,258 & 24,687 & 26,258 & 24,687 \\
\hline
\end{tabular}

Fonte: Prova Brasil e Censo Escolar 2011. Elaboração própria. Nota: Erros-padrão entre parênteses.

Tabela 5: Estimativas dos modelos que relacionam notas, circunstâncias e esforços - escolas com $9^{\circ}$ ano

\begin{tabular}{lcccc}
\hline & Língua Portuguesa & \multicolumn{2}{c}{ Matemática } \\
& $\mathbf{C}$ & $\mathbf{C}+\mathbf{E}$ & $\mathbf{C}$ & $\mathbf{C}+\mathbf{E}$ \\
\hline Rede estadual & $-3,063^{* * *}$ & $-3,242^{* * * *}$ & $-3,654^{* * *}$ & $-3,814^{* * *}$ \\
& $(0,247)$ & $(0,250)$ & $(0,275)$ & $(0,276)$ \\
Capital & $-0,35$ & $-0,453^{*}$ & $-2,793^{* * *}$ & $-1,832^{* * * *}$ \\
& $(0,25)$ & $(0,258)$ & $(0,268)$ & $(0,270)$ \\
Entorno escolar & $-0,280^{* * *}$ & $-0,185^{* * *}$ & $-0,477^{* * *}$ & $-0,357^{* * *}$ \\
& $(0,028)$ & $(0,028)$ & $(0,030)$ & $(0,030)$ \\
Recursos financeiros & $-0,073$ & $-0,078$ & $-0,147$ & $-0,167$ \\
& $(0,110)$ & $(0,110)$ & $(0,124)$ & $(0,124)$ \\
Múltiplas etapas & $-1,238^{* * *}$ & $-1,284^{* * *}$ & $-0,780^{* * *}$ & $-0,791^{* * *}$ \\
& $(0,208)$ & $(0,209)$ & $(0,233)$ & $(0,233)$ \\
Número total de matrículas & $-0,002^{* * *}$ & $-0,001^{* * *}$ & $-0,002^{* * *}$ & $-0,002^{* * *}$ \\
& $(0,000)$ & $(0,000)$ & $(0,000)$ & $(0,000)$ \\
Tamanho das turmas & 0,032 & $0,053^{* * *}$ & $-0,039^{*}$ & $-0,017$ \\
& $(0,021)$ & $(0,021)$ & $(0,023)$ & $(0,023)$ \\
Formação acadêmica do diretor & 0,036 & 0,05 & $-0,221$ & $-0,191$ \\
Experiência do diretor & $(0,187)$ & $(0,187)$ & $(0,205)$ & $(0,203)$ \\
& $1,257^{* * *}$ & $1,053^{* * *}$ & $1,157^{* * *}$ & $0,928^{* * *}$ \\
Formação acadêmica do professor & $(0,180)$ & $(0,180)$ & $(0,201)$ & $(0,200)$ \\
& $0,821^{* * *}$ & 0,237 & $1,191^{* * *}$ & $0,569^{* * *}$ \\
Experiência do professor & $(0,197)$ & $(0,203)$ & $(0,218)$ & $(0,223)$ \\
Tempo de dedicação do professor & $0,883^{* * *}$ & $0,709^{* * *}$ & $1,350^{* * *}$ & $1,172^{* * *}$ \\
& $(0,149)$ & $(0,152)$ & $(0,165)$ & $(0,167)$ \\
Gênero dos alunos e (proporção de meninos) & 0,141 & 0,498 & $0,817^{* *}$ & $1,268^{* * *}$ \\
& $(0,338)$ & $(0,340)$ & $(0,379)$ & $(0,380)$ \\
Raça dos alunos e (proporção de brancos) & $-26,542^{* * *}$ & $-26,214^{* * *}$ & $-5,685^{* * *}$ & $-5,151^{* * *}$ \\
& $(1,103)$ & $(1,111)$ & $(1,214)$ & $(1,212)$ \\
& $16,884^{* * *}$ & $15,205^{* * *}$ & $26,685^{* * *}$ & $24,344^{* * *}$ \\
Fonte: Prova Brasil & $(0,804)$ & $(0,809)$ & $(0,913)$ & $(0,914)$ \\
\hline
\end{tabular}

Fonte: Prova Brasil e Censo Escolar 2011. Elaboração própria. Nota: Erros-padrão entre parênteses. 
Tabela 5: Estimativas dos modelos que relacionam notas, circunstâncias e esforços - escolas com $9^{\circ}$ ano (continuação)

\begin{tabular}{|c|c|c|c|c|}
\hline & \multicolumn{2}{|c|}{ Língua Portuguesa } & \multicolumn{2}{|c|}{ Matemática } \\
\hline & C & $\mathrm{C}+\mathrm{E}$ & $\mathrm{C}$ & $\mathrm{C}+\mathrm{E}$ \\
\hline Atraso escolar & $\begin{array}{c}-18,116^{* * *} \\
(0,921)\end{array}$ & $\begin{array}{c}-15,724^{* * *} \\
(0,929)\end{array}$ & $\begin{array}{c}-19,939^{* * * *} \\
(1,044)\end{array}$ & $\begin{array}{c}-17,199^{* * *} \\
(1,052)\end{array}$ \\
\hline Nível socioeconômico dos alunos & $\begin{array}{l}4,504^{* * *} \\
(0,066)\end{array}$ & $\begin{array}{l}4,346^{* * *} \\
(0,067)\end{array}$ & $\begin{array}{l}4,515^{* * *} \\
(0,077)\end{array}$ & $\begin{array}{l}4,298^{* * *} \\
(0,077)\end{array}$ \\
\hline Conservação do prédio escolar & $\begin{array}{l}0,302^{* * *} \\
(0,065)\end{array}$ & $\begin{array}{l}0,249^{* * *} \\
(0,065)\end{array}$ & $\begin{array}{l}0,342^{* * *} \\
(0,072)\end{array}$ & $\begin{array}{l}0,274^{* * *} \\
(0,072)\end{array}$ \\
\hline Ambiente físico das salas de aula & $\begin{array}{l}0,441^{* *} \\
(0,178)\end{array}$ & $\begin{array}{l}0,437^{* *} \\
(0,178)\end{array}$ & $\begin{array}{l}0,326^{*} \\
(0,197)\end{array}$ & $\begin{array}{l}0,280 \\
(0,196)\end{array}$ \\
\hline Equipamentos & $\begin{array}{l}0,109^{* * *} \\
(0,032)\end{array}$ & $\begin{array}{l}0,090^{* * *} \\
(0,032)\end{array}$ & $\begin{array}{l}0,149^{* * * *} \\
(0,035)\end{array}$ & $\begin{array}{l}0,137^{* * *} \\
(0,035)\end{array}$ \\
\hline Espaço e recursos didático-pedagógicos & $\begin{array}{r}-0,015 \\
(0,048)\end{array}$ & $\begin{array}{r}-0,048 \\
(0,048)\end{array}$ & $\begin{array}{r}-0,022 \\
(0,053)\end{array}$ & $\begin{array}{r}-0,068 \\
(0,052)\end{array}$ \\
\hline Livro didático & $\begin{array}{c}-0,700^{* * *} \\
(0,138)\end{array}$ & $\begin{array}{c}-0,675^{* * *} \\
(0,138)\end{array}$ & $\begin{array}{c}-0,769^{* * *} \\
(0,154)\end{array}$ & $\begin{array}{c}-0,738^{* * *} \\
(0,153)\end{array}$ \\
\hline Uso de recursos pedagógicos & - & $\begin{array}{l}0,144^{* * *} \\
(0,053)\end{array}$ & - & $\begin{array}{c}0,136^{* *} \\
(0,058)\end{array}$ \\
\hline Práticas de ensino tradicionais & - & $\begin{array}{c}-0,304^{* * *} \\
(0,047)\end{array}$ & - & $\begin{array}{c}-0,314^{* * *} \\
(0,052)\end{array}$ \\
\hline Cumprimento curricular & - & $\begin{array}{l}3,384^{* * *} \\
(0,265)\end{array}$ & - & $\begin{array}{l}4,939^{* * *} \\
(0,297)\end{array}$ \\
\hline Alocação dos alunos nas turmas & - & $\begin{array}{l}0,184 \\
(0,180)\end{array}$ & - & $\begin{array}{c}0,064 \\
(0,199)\end{array}$ \\
\hline Uso do tempo escolar & - & $\begin{array}{l}1,276^{* * * *} \\
(0,253)\end{array}$ & - & $\begin{array}{l}2,063^{\text {****}} \\
(0,280)\end{array}$ \\
\hline Liderança do diretor & - & $\begin{array}{l}0,216^{* * *} \\
(0,047)\end{array}$ & - & $\begin{array}{c}0,283^{* * *} \\
(0,052)\end{array}$ \\
\hline Planejamento escolar & - & $\begin{array}{r}-0,222 \\
(0,264)\end{array}$ & - & $\begin{array}{r}-0,380 \\
(0,293)\end{array}$ \\
\hline Conhecimento das avaliações & - & $\begin{array}{l}1,136^{* * *} \\
(0,123)\end{array}$ & - & $\begin{array}{l}1,261^{* * *} \\
(0,132)\end{array}$ \\
\hline $\begin{array}{l}\text { Participação dos professores nas deci- } \\
\text { sões da escola }\end{array}$ & - & $\begin{array}{l}-0,267^{* * *} \\
(0,078)\end{array}$ & - & $\begin{array}{l}-0,463^{* * *} \\
(0,086)\end{array}$ \\
\hline Expectativas de sucesso escolar & - & $\begin{array}{l}1,744^{* * *} \\
(0,166)\end{array}$ & - & $\begin{array}{l}2,009^{* * *} \\
(0,186)\end{array}$ \\
\hline Participação dos pais & - & $\begin{array}{l}0,240 \\
(0,164)\end{array}$ & - & $\begin{array}{l}0,143 \\
(0,183)\end{array}$ \\
\hline Clima escolar & - & $\begin{array}{c}-0,180^{* * *} \\
(0,047)\end{array}$ & - & $\begin{array}{c}-0,156^{* * *} \\
(0,052)\end{array}$ \\
\hline Dummies de UF & Sim & Sim & Sim & Sim \\
\hline Constante & $\begin{array}{l}185,825^{* * *} \\
(1,512)\end{array}$ & $\begin{array}{l}183,288^{* * *} \\
(1,648)\end{array}$ & $\begin{array}{l}184,508^{* * *} \\
(1,700)\end{array}$ & $\begin{array}{l}181,671^{* * *} \\
(1,832)\end{array}$ \\
\hline Número de Observações & 21,060 & 20,317 & 21,060 & 20,317 \\
\hline R2 & 0,550 & 0,565 & 0,565 & 0,584 \\
\hline
\end{tabular}

Fonte: Prova Brasil e Censo Escolar 2011. Elaboração própria. Nota: Erros-padrão entre parênteses. 
Tabela 6: Índices de desigualdade e parcela da desigualdade de oportunidade (para escolas)

\begin{tabular}{|c|c|c|c|c|}
\hline & \multicolumn{2}{|c|}{$5^{\circ}$ ano } & \multicolumn{2}{|l|}{$9^{\circ}$ ano } \\
\hline & Língua Portuguesa & Matemática & Língua Portuguesa & Matemática \\
\hline Índice observado & $\begin{array}{c}0,00612 \% \\
(0,0)\end{array}$ & $\begin{array}{c}0,00696 \% \\
(0,0)\end{array}$ & $\begin{array}{c}0,00302 \% \\
(0,0)\end{array}$ & $\begin{array}{c}0,00360 \% \\
(0,0)\end{array}$ \\
\hline Índice após equalizar circunstâncias e (sem esforços) & $\begin{array}{c}0,00235 \% \\
(0,0)\end{array}$ & $\begin{array}{c}0,00285 \% \\
(0,0)\end{array}$ & $\begin{array}{c}0,00134 \% \\
(0,0)\end{array}$ & $\begin{array}{c}0,00155 \% \\
(0,0)\end{array}$ \\
\hline Efeito das circunstâncias (total) & $\begin{array}{c}61,60000 \% \\
(0,029 \%)\end{array}$ & $\begin{array}{c}59,10000 \% \\
(0,031 \%)\end{array}$ & $\begin{array}{c}55,60000 \% \\
(0,039 \%)\end{array}$ & $\begin{array}{c}56,90000 \% \\
(0,039 \%)\end{array}$ \\
\hline Índice após equalizar circunstâncias e (controlando esforços) & $\begin{array}{c}0,00238 \% \\
(0,0)\end{array}$ & $\begin{array}{c}0,00289 \% \\
(0,0)\end{array}$ & $\begin{array}{c}0,00135 \% \\
(0,0)\end{array}$ & $\begin{array}{c}0,00156 \% \\
(0,0)\end{array}$ \\
\hline $\begin{array}{l}\text { Efeito direto } \\
\text { direto/total }\end{array}$ & $\begin{array}{c}61,10000 \% \\
(0,03100 \%) \\
{[99,2 \%]}\end{array}$ & $\begin{array}{c}58,50000 \% \\
(0,03300 \%) \\
{[99,0 \%]}\end{array}$ & $\begin{array}{c}55,30000 \% \\
(0,03900 \%) \\
{[99,4 \%]}\end{array}$ & $\begin{array}{c}56,70000 \% \\
(0,04000 \%) \\
{[99,5 \%]}\end{array}$ \\
\hline $\begin{array}{l}\text { Efeito indireto } \\
\text { indireto/total }\end{array}$ & $\begin{array}{c}0,50000 \% \\
(0,00900 \%) \\
{[0,8 \%]}\end{array}$ & $\begin{array}{c}0,60000 \% \\
(0,01000 \%) \\
{[1,0 \%]}\end{array}$ & $\begin{array}{c}0,30000 \% \\
(0,00700 \%) \\
{[0,6 \%]}\end{array}$ & $\begin{array}{c}0,30000 \% \\
(0,00700 \%) \\
{[0,5 \%]}\end{array}$ \\
\hline
\end{tabular}

bootstrap. 
Tabela 7: Índices de desigualdade e parcela da desigualdade de oportunidade (para redes)

\begin{tabular}{|c|c|c|c|c|}
\hline & \multicolumn{2}{|l|}{$5^{\circ}$ ano } & \multicolumn{2}{|l|}{$9^{\circ}$ ano } \\
\hline & Língua Portuguesa & Matemática & Língua Portuguesa & Matemática \\
\hline Índice observado & $\begin{array}{c}0,00612 \% \\
(0,0)\end{array}$ & $\begin{array}{c}0,00696 \% \\
(0,0)\end{array}$ & $\begin{array}{c}0,00302 \% \\
(0,0)\end{array}$ & $\begin{array}{c}0,00360 \% \\
(0,0)\end{array}$ \\
\hline Índice após equalizar circunstâncias e (sem esforços) & $\begin{array}{c}0,00302 \% \\
(0,0)\end{array}$ & $\begin{array}{c}0,00363 \% \\
(0,0)\end{array}$ & $\begin{array}{c}0,00171 \% \\
(0,0)\end{array}$ & $\begin{array}{c}0,00210 \% \\
(0,0)\end{array}$ \\
\hline Efeito das circunstâncias (total) & $\begin{array}{c}50,70000 \% \\
(0,032 \%)\end{array}$ & $\begin{array}{c}47,80000 \% \\
(0,032 \%)\end{array}$ & $\begin{array}{c}43,40000 \% \\
(0,036 \%)\end{array}$ & $\begin{array}{c}41,70000 \% \\
(0,037 \%)\end{array}$ \\
\hline Índice após equalizar circunstâncias e (controlando esforços) & $\begin{array}{c}0,00308 \% \\
(0,0)\end{array}$ & $\begin{array}{c}0,00380 \% \\
(0,0)\end{array}$ & $\begin{array}{c}0,00175 \% \\
(0,0)\end{array}$ & $\begin{array}{c}0,00215 \% \\
(0,0)\end{array}$ \\
\hline $\begin{array}{l}\text { Efeito direto } \\
\text { direto/total }\end{array}$ & $\begin{array}{c}49,70000 \% \\
(0,03800 \%) \\
{[98,1 \%]}\end{array}$ & $\begin{array}{c}45,40000 \% \\
(0,04000 \%) \\
{[94,9 \%]}\end{array}$ & $\begin{array}{c}42,10000 \% \\
(0,04600 \%) \\
{[96,9 \%]}\end{array}$ & $\begin{array}{c}40,30000 \% \\
(0,04700 \%) \\
{[96,7 \%]}\end{array}$ \\
\hline $\begin{array}{l}\text { Efeito indireto } \\
\text { indireto/total }\end{array}$ & $\begin{array}{c}1,00000 \% \\
(0,00800 \%) \\
{[1,9 \%]}\end{array}$ & $\begin{array}{c}2,40000 \% \\
(0,00900 \%) \\
{[5,1 \%]}\end{array}$ & $\begin{array}{c}1,30000 \% \\
(0,01000 \%) \\
{[3,1 \%]}\end{array}$ & $\begin{array}{c}1,40000 \% \\
(0,01100 \%) \\
{[3,3 \%]}\end{array}$ \\
\hline
\end{tabular}

bootstrap. 
Tabela 8: Desigualdade de oportunidades de cada circunstância e pesos relativos $-5^{\circ}$ ano

\begin{tabular}{lcccccc}
\hline & \multicolumn{3}{c}{ Língua Portuguesa } & \multicolumn{3}{c}{ Matemática } \\
& Efeito Total & Direto & Indireto & Efeito Total & Direto & Indireto \\
\hline Alunos & $49,700 \%$ & $41,500 \%$ & $8,200 \%$ & $46,100 \%$ & $35,500 \%$ & $10,600 \%$ \\
& $(0,034 \%)$ & $(0,055 \%)$ & $(0,035 \%)$ & $(0,038 \%)$ & $(0,059 \%)$ & $(0,041 \%)$ \\
& {$[72,4 \%]$} & {$[60,5 \%]$} & {$[11,9 \%]$} & {$[63,7 \%]$} & {$[49,0 \%]$} & {$[14,7 \%]$} \\
Diretores e professores & $3,100 \%$ & $-3,400 \%$ & $6,500 \%$ & $3,300 \%$ & $-5,000 \%$ & $8,300 \%$ \\
& $(0,028 \%)$ & $(0,052 \%)$ & $(0,044 \%)$ & $(0,030 \%)$ & $(0,053 \%)$ & $(0,047 \%)$ \\
Dotação de recursos & {$[4,5 \%]$} & {$[-5,0 \%]$} & {$[9,5 \%]$} & {$[4,6 \%]$} & {$[-6,9 \%]$} & {$[11,5 \%]$} \\
& $4,700 \%$ & $-2,600 \%$ & $7,400 \%$ & $5,300 \%$ & $-4,000 \%$ & $9,300 \%$ \\
Contexto de gestão & $(0,034 \%)$ & $(0,056 \%)$ & $(0,045 \%)$ & $(0,035 \%)$ & $(0,056 \%)$ & $(0,048 \%)$ \\
& {$[6,9 \%]$} & {$[-3,8 \%]$} & {$[10,7 \%]$} & {$[7,3 \%]$} & {$[-5,6 \%]$} & {$[12,9 \%]$} \\
& $11,100 \%$ & $5,900 \%$ & $5,200 \%$ & $17,700 \%$ & $10,200 \%$ & $7,500 \%$ \\
& $(0,066 \%)$ & $(0,075 \%)$ & $(0,047 \%)$ & $(0,064 \%)$ & $(0,077 \%)$ & $(0,046 \%)$ \\
& {$[16,2 \%]$} & {$[8,6 \%]$} & {$[7,6 \%]$} & {$[24,4 \%]$} & {$[14,1 \%]$} & {$[10,3 \%]$} \\
\hline
\end{tabular}

Fonte: Prova Brasil e Censo Escolar 2011. Elaboração própria. Nota: Erros-padrão entre parênteses, gerados via bootstrap. Valor entre colchetes corresponde à parcela do efeito da desigualdade de oportunidades sobre a soma das desigualdades em cada coluna.

Tabela 9: Desigualdade de oportunidades de cada circunstância e pesos relativos $-9^{\circ}$ ano

\begin{tabular}{lcccccc}
\hline & \multicolumn{3}{c}{ Língua Portuguesa } & \multicolumn{3}{c}{ Matemática } \\
& Efeito Total & Direto & Indireto & Efeito Total & Direto & Indireto \\
\hline Alunos & $41,100 \%$ & $36,800 \%$ & $4,300 \%$ & $38,600 \%$ & $33,600 \%$ & $5,000 \%$ \\
& $(0,044 \%)$ & $(0,054 \%)$ & $(0,032 \%)$ & $(0,051 \%)$ & $(0,061 \%$ & $(0,033 \%)$ \\
Diretores e professores & {$[102,4 \%]$} & {$[91,7 \%]$} & {$[10,7 \%]$} & {$[101,3 \%]$} & {$[88,2 \%]$} & {$[13,1 \%]$} \\
& $3,000 \%$ & $-1,700 \%$ & $4,600 \%$ & $3,300 \%$ & $-2,200 \%$ & $5,600 \%$ \\
& $(0,033 \%)$ & $(0,050 \%)$ & $(0,040 \%)$ & $(0,034 \%)$ & $(0,054 \%)$ & $(0,040 \%)$ \\
Dotação de recursos & {$[7,4 \%]$} & {$[-4,1 \%]$} & {$[11,6 \%]$} & {$[8,7 \%]$} & {$[5,8 \%]$} & {$[14,6 \%]$} \\
& $3,300 \%$ & $-1,700 \%$ & $5,000 \%$ & $3,300 \%$ & $-2,500 \%$ & $5,800 \%$ \\
Contexto de gestão & $(0,037 \%)$ & $(0,052 \%)$ & $(0,040 \%)$ & $(0,035 \%)$ & $(0,054 \%)$ & $(0,040 \%)$ \\
& {$[8,3 \%]$} & {$[-4,1 \%]$} & {$[12,4 \%]$} & {$[8,7 \%]$} & {$[-6,6 \%]$} & {$[15,3 \%]$} \\
& $-7,300 \%$ & $-7,600 \%$ & $0,300 \%$ & $-7,200 \%$ & $-7,500 \%$ & $0,300 \%$ \\
& $(0,089 \%)$ & $(0,090 \%)$ & $(0,041 \%)$ & $(0,101 \%)$ & $(0,102 \%)$ & $(0,044 \%)$ \\
\hline
\end{tabular}

Fonte: Prova Brasil e Censo Escolar 2011. Elaboração própria. Nota: Erros-padrão entre parênteses, gerados via bootstrap. Valor entre colchetes corresponde à parcela do efeito da desigualdade de oportunidades sobre a soma das desigualdades em cada coluna. 
Tabela 10: Peso de cada circunstância sobre o efeito total da desigualdade de oportunidades

\begin{tabular}{lcccc}
\hline & \multicolumn{2}{c}{$\mathbf{5}^{\mathbf{0}}$ ano } & \multicolumn{2}{c}{$\mathbf{9}^{\mathbf{0}}$ ano } \\
& Língua Portuguesa & Matemática & Língua Portuguesa & Matemática \\
\hline Nível socioeconômico dos alunos & $43,800 \%$ & $39,100 \%$ & $39,700 \%$ & $37,500 \%$ \\
Composição do corpo discente & $(0,039 \%)$ & $(0,043 \%)$ & $(0,043 \%)$ & $(0,048 \%)$ \\
Perfil dos gestores & $20,900 \%$ & $19,800 \%$ & $21,500 \%$ & $26,100 \%$ \\
& $(0,048 \%)$ & $(0,049 \%)$ & $(0,058 \%)$ & $(0,052 \%)$ \\
Perfil dos docentes & $1,600 \%$ & $1,400 \%$ & $2,300 \%$ & $2,200 \%$ \\
& $(0,028 \%)$ & $(0,026 \%)$ & $(0,032 \%)$ & $(0,033 \%)$ \\
Tempo de dedicação do professor & $2,800 \%$ & $2,900 \%$ & $2,600 \%$ & $2,800 \%$ \\
& $(0,030 \%)$ & $(0,029 \%)$ & $(0,031 \%)$ & $(0,033 \%)$ \\
Recursos financeiros & $1,300 \%$ & $1,000 \%$ & $1,700 \%$ & $1,700 \%$ \\
& $(0,028 \%)$ & $(0,026 \%)$ & $(0,031 \%)$ & $(0,032 \%)$ \\
Manutenção e conservação da escola & $1,500 \%$ & $1,400 \%$ & $1,700 \%$ & $1,700 \%$ \\
Espaços e recursos didático-pedagógicos & $(0,028 \%)$ & $(0,027 \%)$ & $(0,031 \%)$ & $(0,032 \%)$ \\
Equipamentos & $2,300 \%$ & $2,200 \%$ & $2,600 \%$ & $2,500 \%$ \\
& $(0,030 \%)$ & $(0,031 \%)$ & $(0,034 \%)$ & $(0,034 \%)$ \\
Leis e normas & $2,100 \%$ & $2,300 \%$ & $1,700 \%$ & $1,700 \%$ \\
& $(0,035 \%)$ & $(0,035 \%)$ & $(0,036 \%)$ & $(0,035 \%)$ \\
Localização & $3,100 \%$ & $3,000 \%$ & $2,600 \%$ & $2,800 \%$ \\
& $(0,034 \%)$ & $(0,036 \%)$ & $(0,035 \%)$ & $(0,037 \%)$ \\
Complexidade de gestão & $11,800 \%$ & $18,000 \%$ & $-6,000 \%$ & $-6,900 \%$ \\
& $(0,069 \%)$ & $(0,065 \%)$ & $(0,092 \%)$ & $(0,094 \%)$ \\
Tamanho das turmas & $1,600 \%$ & $1,600 \%$ & $2,000 \%$ & $2,800 \%$ \\
& $(0,028 \%)$ & $(0,028 \%)$ & $(0,031 \%)$ & $(0,033 \%)$ \\
& $0,800 \%$ & $0,900 \%$ & $1,000 \%$ & $1,700 \%$ \\
\hline Fonte: Prova Brasil e Cen & $(0,029 \%)$ & $(0,027 \%)$ & $(0,032 \%)$ & $(0,033 \%)$ \\
van & $1,100 \%$ & $1,100 \%$ & $1,700 \%$ & $1,900 \%$ \\
& $(0,028 \%)$ & $(0,028 \%)$ & $(0,032 \%)$ & $(0,035 \%)$ \\
\hline
\end{tabular}

Fonte: Prova Brasil e Censo Escolar 2011. Elaboração própria. Nota: Erros-padrão entre parênteses, gerados via bootstrap. 


\section{Apêndice $A$}


Tabela A.1: Descrição da construção das variáveis/indicadores por dimensão

\begin{tabular}{|c|c|c|}
\hline Dimensão e Item & Indicador & Variáveis \\
\hline \multicolumn{3}{|l|}{ Leis e normas } \\
\hline Dependência administrativa ${ }^{1}$ & & dummy (1: rede estadual; 0: rede municipal) \\
\hline Unidade da Federação $^{1}$ & & dummies de UF \\
\hline Localização & Índice: soma ( 0 a 19$)$ & \\
\hline$\overline{\text { Identificador do município }^{1}}$ & & dummy (1: capital; 0: demais municípios) \\
\hline Atentado à vida: professores, funcionários, alunos $(2)^{2}$ & & dummies (1: sim; 0: não) \\
\hline Furto, roubo: professores, funcionários, alunos $(4)^{2}$ & & dummies (1: sim; 0: não) \\
\hline Furto, roubo, depredação, pichação $(8)^{2}$ & & dummies (1: sim; 0: não) \\
\hline Consumo, tráfico drogas $(5)^{2}$ & & dummies (1: sim; 0: não) \\
\hline Recursos financeiros & Índice: soma ( 0 a 4$)$ & \\
\hline Insuficiência de recursos financeiros ${ }^{2}$ & & dummy (0: sim, grave; sim, não grave; 1: não) \\
\hline Recursos de financiamento $(3)^{2}$ & & dummies (1: sim; 0: não) \\
\hline \multicolumn{3}{|l|}{ Complexidade de gestão } \\
\hline$\overline{\text { Número de matrículas }}{ }^{5}$ & & total de matrículas da escola \\
\hline Etapa de ensino ${ }^{5}$ & & dummy (1: escola oferece mais de uma etapa de ensino; 0: c.c.) \\
\hline \multicolumn{3}{|r|}{ 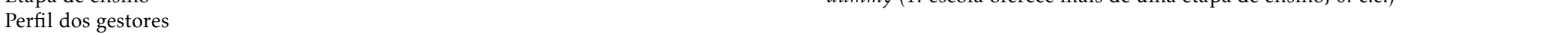 } \\
\hline$\overline{\text { Área do curso de pós-graduaçao }}{ }^{2}$ & & dummy (1: educação, enfatizando gestão; 0: c.c.) \\
\hline Tempo como diretor ${ }^{2}$ & & dummy (1: cinco anos ou mais; 0 : menos de cinco anos) \\
\hline \multicolumn{3}{|l|}{ Perfil dos docentes } \\
\hline Formação: & Índice: soma (0 a 2) & \\
\hline Cursos de pós-graduação ${ }^{3}$ & & dummy (1: fez pós-graduação; 0: c.c.) \\
\hline Fez formação continuada ${ }^{3}$ & & dummy (1: sim; 0: não) \\
\hline Experiência: & Índice: soma (0 a 2) & \\
\hline Tempo como professor ${ }^{3}$ & & dummy (1: 15 anos ou mais; $0:$ menos de 15 anos) \\
\hline Tempo como professor na escola ${ }^{3}$ & & dummy (1: 5 anos ou mais; 0 : menos de 5 anos) \\
\hline Tempo de dedicação do professor & Índice: soma ( 0 a 3 ) & \\
\hline$\overline{\text { Exerce outra atividade }{ }^{3}}$ & & dummy (1: não; 0: sim, na área de educação; sim, fora da área de educação) \\
\hline Em quantas escolas trabalha ${ }^{3}$ & & dummy (1: em uma escola; 0: mais de uma escola) \\
\hline Alta rotatividade do corpo docente ${ }^{2}$ & & dummy (1: sim, grave; sim, não grave; 0: não) \\
\hline Composição do corpo discente & & \\
\hline$\overline{\operatorname{Sexo}^{4}}$ & - & dummy (1: menino; 0: menina) \\
\hline Distorção idade-série 4 & & $\begin{array}{l}\text { dummy }(=1 \text { : atrasado; }=0 \text { : c.c.). Construída a partir da idade ou ano de nasci- } \\
\text { mento do aluno }\end{array}$ \\
\hline Cor, raça ${ }^{4}$ & - & dummy (1: branco; 0: c.c.) \\
\hline
\end{tabular}

\footnotetext{
Nota: números entre parênteses correspondem a quantidade de perguntas que compõem cada item. Fontes: ${ }^{1}$ Censo Escolar 2011 (escolas); ${ }^{2}$ Prova Brasil 2011 (diretores);

${ }^{3}$ Prova Brasil 2011 (professores); ${ }^{4}$ Prova Brasil 2011 (alunos); ${ }^{5}$ Censo Escolar 2011 (turmas).
} 
Tabela A.1: Descrição da construção das variáveis/indicadores por dimensão (continuação)

\begin{tabular}{|c|c|c|}
\hline Dimensão e Item & Indicador & Variáveis \\
\hline NSE alunos & Índice: soma (0 a 34) & \\
\hline$\overline{\mathrm{TV} \text { em cores }} 4$ & & categórica ( $0:$ não; $1: \operatorname{sim}$, uma; $2: \operatorname{sim}$, duas; $3: \operatorname{sim}$, três ou mais) \\
\hline Rádio $^{4}$ & & categórica ( $0:$ não; $1: \operatorname{sim}$, um; $2: \operatorname{sim}$, dois; $3: \operatorname{sim}$, três ou mais) \\
\hline Videocassete ou $\mathrm{DVD}^{4}$ & & dummy (1: sim; 0: não) \\
\hline Geladeira $^{4}$ & & categórica ( $0:$ não; $1: \operatorname{sim}$, uma; 2 : sim, duas) \\
\hline Freezer $(2)^{4}$ & & dummies (1: sim; 0: não) \\
\hline Máquina de lavar roupa ${ }^{4}$ & & dummy (1: sim; 0: não) \\
\hline Carro $^{4}$ & & categórica ( $0:$ não; 1 : sim, um; $2: \operatorname{sim}$, dois; $3: \operatorname{sim}$, três ou mais) \\
\hline Computador ${ }^{4}$ & & categórica (0: não; $1:$ sim, sem internet; $2:$ sim, com internet) \\
\hline Banheiro $^{4}$ & & categórica (0: não; $1: \operatorname{sim}$, um; $2: \operatorname{sim}$, dois; $3: \operatorname{sim}$, três; $4: \operatorname{sim}$, mais de três) \\
\hline Empregada doméstica ${ }^{4}$ & & categórica ( 0 : não; 1 : diarista; 2 : todos os dias; 3 : duas ou mais, todos os dias) \\
\hline Quartos para dormir ${ }^{4}$ & & categórica (0: não; $1: \operatorname{sim}$, um; $2: \operatorname{sim}$, dois; $3: \operatorname{sim}$, três; $4: \operatorname{sim}$, mais de três) \\
\hline Até que série mãe estudou 4 & & $\begin{array}{l}\text { categórica (0: nunca; 1: EF1 incomp.; 2: EF2 incomp.; 3: EM incomp.; 4: EM } \\
\text { completo; 5: ES) }\end{array}$ \\
\hline Mãe sabe ler e escrever ${ }^{4}$ & & dummy (1: sim; 0: não) \\
\hline \multicolumn{3}{|l|}{ Manutenção e conservação da escola } \\
\hline 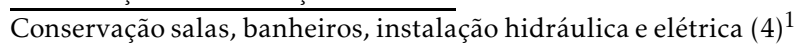 & Índice: soma ( 0 a 4$)$ & dummies (1: bom; 0: regular, ruim) \\
\hline Salas de aulas arejadas e iluminadas $(2)^{1}$ & Índice: soma (0 a 2) & dummies (1: sim; 0: não) \\
\hline Equipamentos & Índice: soma ( 0 a 15) & \\
\hline \multicolumn{3}{|l|}{ Existência e condiçoes de uso: } \\
\hline $\begin{array}{l}\text { Computador, internet, impressora (professor, administração) } \\
(4)^{1}\end{array}$ & & dummies (1: bom; 0: regular, ruim, inexistente) \\
\hline Copiadora, mimeógrafo, retroprojetor, projetor slides $(4)^{1}$ & & dummies (1: bom; 0: regular, ruim, inexistente) \\
\hline TV, vídeo, DVD, parabólica $(3)^{1}$ & & dummies (1: bom; 0: regular, ruim, inexistente) \\
\hline Telefone, FAX $(2)^{1}$ & & dummies (1: bom; 0: regular, ruim, inexistente) \\
\hline Câmera fotográfica, som $(2)^{1}$ & & dummies (1: bom; 0: regular, ruim, inexistente) \\
\hline \multicolumn{3}{|l|}{ Espaços e disponibilidade de recursos didático-pedagógicos } \\
\hline$\overline{\text { Existência e condições de uso: }}$ & Índice: soma (0 a 11) & \\
\hline Computador, internet (alunos) $(2)^{1}$ & & dummies (1: bom; 0: regular, ruim, inexistente) \\
\hline Fitas de vídeo, DVD's $(2)^{1}$ & & dummies (1: bom; 0: regular, ruim, inexistente) \\
\hline Biblioteca, laboratório, auditório, quadra $(4)^{1}$ & & dummies (1: bom; 0: regular, ruim, inexistente) \\
\hline Salas música, artes, leitura $(3)^{1}$ & & dummies (1: bom; 0: regular, ruim, inexistente) \\
\hline
\end{tabular}

Nota: números entre parênteses correspondem a quantidade de perguntas que compõem cada item. Fontes: ${ }^{1}$ Censo Escolar 2011 (escolas); ${ }^{2}$ Prova Brasil 2011 (diretores); ${ }^{3}$ Prova Brasil 2011 (professores); ${ }^{4}$ Prova Brasil 2011 (alunos); ${ }^{5}$ Censo Escolar 2011 (turmas). 
Tabela A.1: Descrição da construção das variáveis/indicadores por dimensão (continuação)

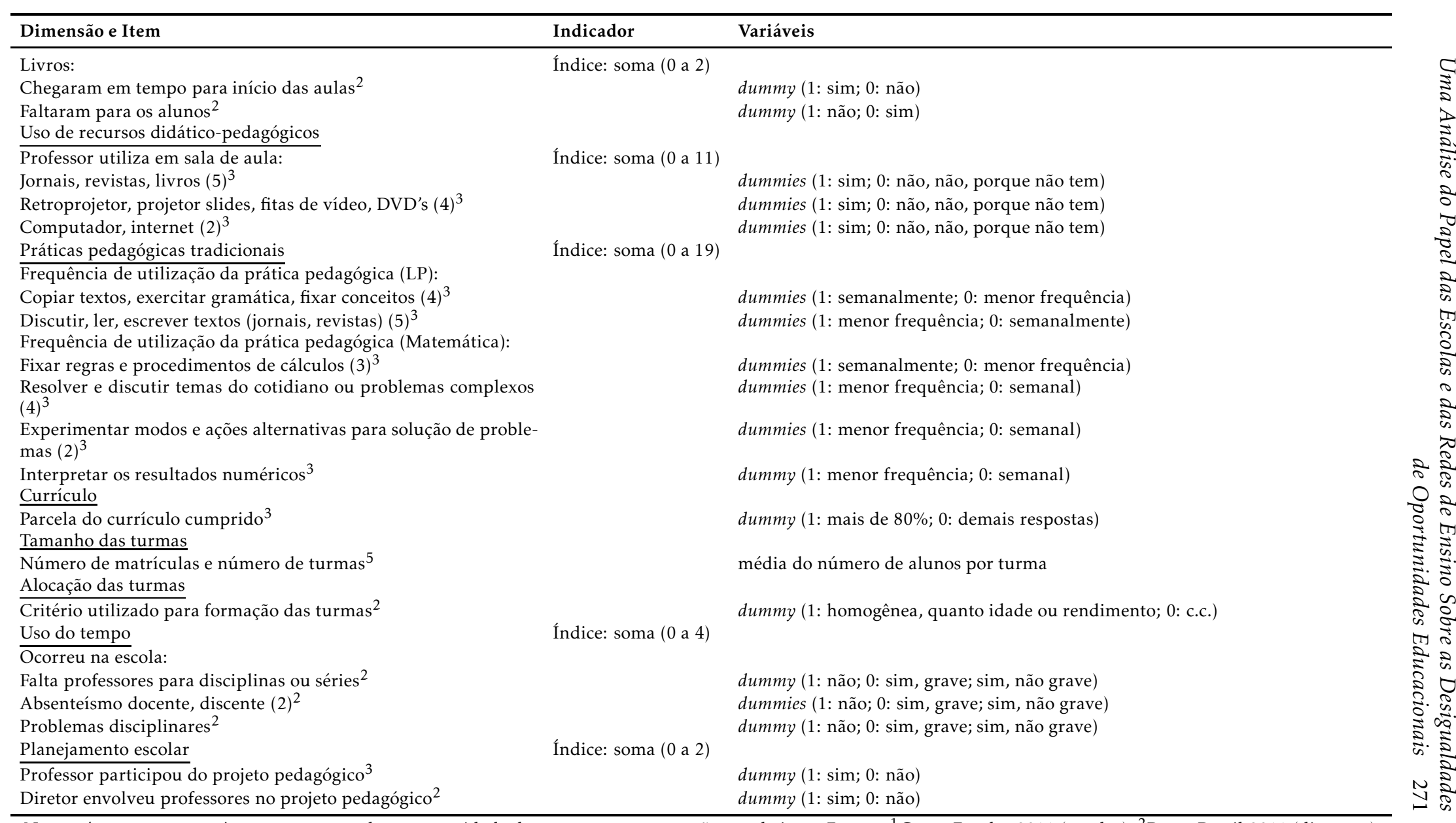

Nota: números entre parênteses correspondem a quantidade de perguntas que compõem cada item. Fontes: ${ }^{1}$ Censo Escolar 2011 (escolas); ${ }^{2}$ Prova Brasil 2011 (diretores);

${ }^{3}$ Prova Brasil 2011 (professores); ${ }^{4}$ Prova Brasil 2011 (alunos); ${ }^{5}$ Censo Escolar 2011 (turmas). 
Tabela A.1: Descrição da construção das variáveis/indicadores por dimensão (continuação)

\begin{tabular}{|c|c|c|}
\hline Dimensão e Item & Indicador & Variáveis \\
\hline Liderança do diretor & Índice: soma (0 a 9) & \\
\hline Diretor motiva, estimula, gera comprometimento $(3)^{3}$ & & dummies (1: concordo totalmente; 0: c.c.) \\
\hline Respeito e confiança professor-diretor $(3)^{3}$ & & dummies (1: concordo totalmente; 0: c.c.) \\
\hline Diretor prioriza aprendizado, manutenção e normas $(3)^{3}$ & & dummies (1: concordo totalmente; 0 : c.c.) \\
\hline Participação dos professores nas decisões/coesão & Índice: soma (0 a 6$)$ & \\
\hline Participo das decisões ${ }^{3}$ & & dummy (1: concordo totalmente; 0: demais respostas) \\
\hline Professores consideram minhas ideias ${ }^{3}$ & & dummy (1: concordo totalmente; $0:$ demais respostas) \\
\hline Levo em consideração ideias dos colegas 3 & & dummy (1: concordo totalmente; 0 : demais respostas) \\
\hline Ensino influenciado pela troca de ideias dos professores ${ }^{3}$ & & dummy (1: concordo totalmente; 0 : demais respostas) \\
\hline Professores coordenam conteúdo das disciplinas entre séries ${ }^{3}$ & & dummy (1: concordo totalmente; $0:$ demais respostas) \\
\hline Há colaboração para o funcionamento da escola ${ }^{3}$ & & dummy (1: concordo totalmente; $0:$ demais respostas) \\
\hline Conhecimento dos resultados educacionais & & \\
\hline Professor conhece IDEB (escola, município, estado) $(3)^{3}$ & & dummies (1: sim; 0: não) \\
\hline Expectativa em relação ao sucesso dos alunos & Índice: soma (0 a 2) & \\
\hline Quantos alunos concluirão o ensino médio ${ }^{3}$ & & dummy (1: quase todos; 0: c.c.) \\
\hline Quantos alunos concluirão o ensino superior ${ }^{3}$ & & dummy (1: mais da metade; 0 : c.c.) \\
\hline Participação dos pais & Índice: soma (0 a 2) & \\
\hline $\bar{O}$ conselho de escola é composto por pais ${ }^{2}$ & & dummy (1: sim; 0: não) \\
\hline Quantas vezes o conselho se reuniu ${ }^{2}$ & & dummy (1: 3 vezes ou mais; $0:$ demais respostas) \\
\hline Clima escolar & Índice: soma ( 0 a 21$)$ & \\
\hline$\overline{\text { Ameaça, agressão verbal e física }(21)^{3}}$ & & dummies (1: sim; 0: não) \\
\hline
\end{tabular}

Nota: números entre parênteses correspondem a quantidade de perguntas que compõem cada item. Fontes: ${ }^{1}$ Censo Escolar 2011 (escolas); ${ }^{2}$ Prova Brasil 2011 (diretores);

${ }^{3}$ Prova Brasil 2011 (professores); ${ }^{4}$ Prova Brasil 2011 (alunos); ${ }^{5}$ Censo Escolar 2011 (turmas). 